\title{
Identification of gene biomarkers and immune cell infiltration characteristics in rectal cancer
}

\author{
Lina Wen ${ }^{1,2}$, Zongqiang $\mathrm{Han}^{3}$, Yanlin $\mathrm{Du}^{4}$ \\ ${ }^{1}$ Department of Clinical Nutrition, Beijing Shijitan Hospital, Capital Medical University, Beijing, China; ${ }^{2}$ Department of Oncology, Capital Medical \\ University; Beijing Institute of Integrated Chinese and Western Medicine Oncology, Beijing, China; ${ }^{3}$ Department of Laboratory Medicine, Beijing \\ Xiaotangshan Hospital, Beijing, China; ${ }^{4}$ Department of Oncology, Wangjing Hospital, China Academy of Chinese Medical Sciences, Beijing, China \\ Contributions: (I) Conception and design: L Wen; (II) Administrative support: Y Du; (III) Provision of study materials or patients: Y Du; (IV) \\ Collection and assembly of data: L Wen, Z Han; (V) Data analysis and interpretation: L Wen, Y Du; (VI) Manuscript writing: All authors; (VII) Final \\ approval of manuscript: All authors.
}

Correspondence to: Yanlin Du. No. 6 Central South Road Wangjing, Beijing 100102, China. Email: lyddyl@163.com.

Background: Compared with colon cancer, the increase of morbidity is more significant for rectal cancer. The current study set out to identify novel and critical biomarkers or features that may be used as promising targets for early diagnosis and treatment monitoring of rectal cancer.

Methods: Microarray datasets of rectal cancer with a minimum sample size of 30 and RNA-sequencing datasets of rectal adenocarcinoma (READ) were downloaded from the Gene Expression Omnibus (GEO) database and The Cancer Genome Atlas (TCGA) database. The method of robust rank aggregation was utilized to integrate differentially expressed genes (DEGs). The protein-protein interaction (PPI) network of the DEGs was structured using the STRING platform, and hub genes were identified using the Cytoscape plugin cytoHubba and an UpSet diagram. R software was employed to perform functional enrichment analysis. Receiver operating characteristic (ROC) curves based on the GEO data and Kaplan-Meier curves based on the TCGA data were drawn to assess the diagnostic and prognostic values of the hub genes. Immune cell infiltration analysis was conducted with CIBERSORT, and the diagnostic value and correlations between prognostic genes and infiltrated immune cells were analyzed by principal component analysis (PCA), ROC curves, and correlation scatter plots.

Results: A total of 137 robust DEGs were obtained by integrating datasets in GEO. Twenty-four hub genes, including CHGA, TTR, SAA1, SPP1, MMP1, TGFBI, COL1A1, and PCK1, were identified as a diagnostic gene biomarker group for rectal cancer, and SAA1, SPP1, and SI were identified as potential novel prognostic biomarkers. Functionally, the hub genes were mainly involved in the rectal cancer related interleukin (IL)-17 and proximal tubule bicarbonate reclamation pathways. Twelve sensitive infiltrated immune cells were identified, and were correlated with prognostic genes.

Conclusions: The integrated gene biomarker group combined with immune cell infiltration can effectively indicate rectal cancer.

Keywords: Rectal cancer; diagnosis; prognosis; biomarker; immune cell infiltration

Submitted Apr 22, 2021. Accepted for publication Jun 04, 2021.

doi: 10.21037/jgo-21-255

View this article at: https://dx.doi.org/10.21037/jgo-21-255

\section{Introduction}

Colorectal cancer (CRC) is one of the highest incidence cancers in the world, and it ranks second in the United States for cancer-related mortality (1). CRC can be divided into 2 major categories: rectal cancer and colon cancer. In patients with CRC, the rectum is the more frequently affected site compared to colon. In China, the incidence rate is significantly higher in males than females. Common 
early detection methods for CRC involve colonoscopic, fecal, and blood sample examinations. According to the tumor size, location, and degree, as well as genetic changes and the patient's health status, CRC treatment can include surgery, chemotherapy, radiotherapy, molecular-targeted therapy, and immunotherapy (2-5).

It is important to note that rectal cancer and colon cancer are not identical, and appropriate treatment based on their own characteristics is of great importance. Rectal cancers account for about $30 \%$ of CRCs and the incidence rate increased more significantly compared to colon cancer (6). Early diagnosis or screening may reduce the morbidity of rectal cancer effectively. Currently, the standard treatment plan for locally advanced rectal cancer is neoadjuvant chemoradiotherapy (nCRT) followed by the total mesorectal excision, but there are a lack of specific biomarkers to monitor treatment effect $(7,8)$. Thus, sensitive and reliable biomarkers are necessary to improve the early diagnosis and treatment of the disease.

Biomarkers based on tissue or blood samples may have a certain sensitivity and specificity for early prediction of disease occurrence or treatment response. To date, methods for the early diagnosis and treatment of CRC have been widely researched. For rectal cancer, the biomarkers that have been found, including gene expression profiles, DNA mutation and methylation, single-nucleotide polymorphism, circulating cell-free nucleic acids, microRNAs, long noncoding RNAs, antigens, enzymes, amino acids, lipids, circulating tumor cells (CTCs), tumor immune cell infiltration, and immune inflammatory cytokines (9). However, these biomarkers have not been fully applied in the clinic setting. A possible reason for this is the limitation of biomarker research. Firstly, the expression of a single biomarker can vary greatly depending on race, region, or study cohort (especially sample size), so a single biomarker does not have universal applicability. Secondly, the human body is a life system with multiple synergistic biological functions, and a single biomarker cannot fully reflect the state of the patient's disease or body; therefore, the integration of different biomarkers of the same category or even different biomarker categories is needed. An increasing bank of studies shows that integrated biomarkers are more significant compared with a single biomarker for the diagnosis and treatment of diseases.

Abnormal gene expression may play a key mechanistic role in cancer initiation. The occurrence of many types of cancers, results from the imbalance of expression of multiple genes. Therefore, variance in gene expression can provide clues about cancer occurrence during the early stage. The screening of differentially expressed genes (DEGs) between cancer patients and healthy individuals can be an effective way to discover early biomarkers. Besides gene regulation, the tumor microenvironment (TME) also performs a vital role in the initiation and progress of cancer. Immune cells are important constituents of the TME. It has been recognized that the immune system plays an irreplaceable role in cancer. Genomic changes lead to the production of tumor antigens, which are recognized by the immune system as non self sources. In this case, cellular immune response is triggered. The immune system plays a role in immune surveillance through the way that immune cells infiltrated into the tumor microenvironment and regulated tumor progression. As one of the characteristics of cancer, immune cell infiltration is a key factor affecting the outcome of cancer immunotherapy. Immunotherapy can also affect the infiltration level of immune cells in tumor tissues. Previous studies have shown that the number of tumor infiltrating lymphocytes (TILs) is closely associated with the prognosis of CRC, for instance, a high density of $\mathrm{CD} 8+\mathrm{T}$ lymphocytes is related to a better prognosis (10). The cytotoxic lymphocyte infiltration and its related immunogenomic pathways may be effective targets for CRC (11).

Considering the limitations of a single biomarker and the importance of tumor microenvironment, we propose gene biomarkers combined with tumor immune cell infiltration maybe a more effective indicator of disease progression. The reliability of biomarkers can be improved by clinical research based on different countries, multiple centers, and a large sample size. Therefore, in this investigation, rectal cancer microarray datasets with a sample size of more than 30 in the Gene Expression Omnibus (GEO) database were integrated using the robust rank aggregation (RRA) method to obtain the DEGs between normal and tumor tissue samples. The functions of robust DEGs were subsequently annotated through enrichment analyses of Gene Ontology (GO) and Kyoto Encyclopedia of Genes and Genomes (KEGG) pathway $(12,13)$. Then, the proteinprotein interaction (PPI) network of the DEGs was set up to analyze the hub genes, and the survival analysis was also carried out to screen the prognostic genes based on a rectal adenocarcinoma (READ) dataset in The Cancer Genome Atlas (TCGA) database. Furthermore, the CIBERSORT algorithm was adopted to investigate the immune cell infiltration state of rectal cancer tissue samples in comparison with normal ones, in order to find immunology characteristics of rectal cancer. We aim to integrate genetic 
and immunological features as precise biomarkers for rectal cancer.

We present the following article in accordance with the REMARK and MDAR reporting checklist (available at https://dx.doi.org/10.21037/jgo-21-255).

\section{Methods}

The study was conducted in accordance with the Declaration of Helsinki (as revised in 2013). Since this was a retrospective database study based on a public database, approval from the ethics committee was not required.

\section{Data collection and processing}

The platform annotation document and matrix files of microarray datasets of rectal cancer were selected and downloaded from the GEO database (https://www.ncbi. nlm.nih.gov/geo/) according to the following inclusion criteria: (I) species were limited to Homo sapiens; (II) the minimum sample size was 30; (III) the experimental type of expression profiling was array; and (IV) both normal tissue samples and tumor tissue samples were available. Only 2 datasets GSE87211 and GSE90627 were included. There were 160 normal and 203 rectal cancer tissue samples in the GSE87211dataset, and 96 normal and 32 rectal cancer tissue samples in the GSE90627 dataset. The platforms were GPL13497 and GPL17077, respectively. The DEGs between the normal and rectal cancer tissue samples in each dataset were identified with the limma package in R4.0.2 (R Foundation for Statistical Computing, Vienna, Austria). The cut-off criteria were: $\mid \log 2$ fold change $(\mathrm{FC}) \mid>1$ with $\mathrm{P}$ value $<0.05$. Additionally, the transcriptome profiles and corresponding clinical information of patients with READ were downloaded from the TCGA database (https://portal. gdc.cancer.gov/) for a survival analysis, which involved 2 normal and 84 READ tissue samples.

\section{Robust DEG identification}

The RRA method was used to integrate the 2 microarray datasets, and the robust DEGs were analyzed with $\mathrm{R}$ package Robust Rank Aggreg. Robust DEGs with I log2FC I $>1$ and $\mathrm{P}$ value $<0.05$ were considered to be Significant.

\section{GO and KEGG enrichment analyses}

GO enrichment analyses including molecular function
(MF), biological process (BP), cellular component (CC), and KEGG enrichment analyses were further performed, and the results were visualized with $\mathrm{R}$ packages including "digest", "GOplot", "clusterprofiler", "org.Hs.eg.db", "enrichplot", and "ggplot2". P value $<0.05$ was deemed to have statistical significance.

\section{Hub gene identification in the DEG network}

The robust DEGs were put into the STRING database to obtain the PPI network with the confidence score set at 0.4. The results were visualized with the Cytoscape v3.6.0 software, in which the MCODE plugin was applied for identification of the significant modules in the PPI network. In line with previous research (14), the cytoHubba plugin in Cytoscape was used to perform an integrated analysis of multiple algorithms for topological parameters including Maximal Clique Centrality (MCC), Density of Maximum Neighborhood Component (DMNC), Maximum Neighborhood Component (MNC), Degree, Edge Percolated Component (EPC), BottleNeck, EcCentricity, Closeness, Radiality, and Betweenness. Hub genes involved in the regulation of rectal cancer were screened based on the scores of above 10 topological parameters.

\section{Biological value of bub genes}

Expression distribution, correlation, and receiver operating characteristic (ROC) curve analyses of the hub genes were performed with $\mathrm{R}$ package. The clinical information and corresponding RNA-seq-Fragments Per Kilobase of Exon Per Million Fragments Mapped (FPKM) data of patients with READ in the TCGA were extracted for a survival analysis of the screened hub genes. The survival and survminer packages of $\mathrm{R}$ language were used for the analysis, with the level of statistical significance set at $\mathrm{P}<0.05$.

\section{Immune infiltration analysis}

The expression matrix of 22 types of immune cells was obtained using the CIBERSORT algorithm. The relative abundance of 22 types of immune cells was extracted for each sample, and the DEGs between normal and rectal cancer tissue samples were filtered by $\mathrm{P}$ value $<0.05$ using R packages "ggpubr" and "cluster". Then, the differences between normal and rectal cancer tissue samples were uncovered by performing principal component analysis (PCA). The correlation between each other of infiltrated 
immune cells was analyzed using R package "corrplot".

\section{Association of prognostic bub gene expression with immune cell infiltration}

To explore the relationships between prognostic hub genes and infiltrated immune cells, correlation scatter plots were drawn using R packages "ggplot2", "ggpubr" and "ggpmisc". The evaluation criteria were as follows: a correlation coefficient $|R|$ between $0.8-1.0$ stood for a very strong correlation; $0.6-0.8$ stood for a strong correlation; 0.4-0.6 stood for a moderate correlation; $0.2-0.4$ stood for a weak correlation; and 0.0-0.2 stood for a very weak or no correlation.

\section{Statistical analysis}

The statistical analyses were performed using $\mathrm{R}$ 4.0.2 (https://www.r-project.org/) and ActivePerl (https://www. activestate.com/). Plots were drawn with the $\mathrm{R}$ package software. Correlation analyses were also performed using the $\mathrm{R}$ package software. All the statistical tests were 2 -sided, and $\mathrm{P}<0.05$ was considered statistically significant.

\section{Results}

\section{Clinical characteristics}

Among the cases in the GSE87211 dataset, there were $248(68.32 \%)$ males and $115(31.68 \%)$ females, with ages ranging from 35.7 to 81.5 years old $(62.90 \pm 9.69$ years old); for 2 cases, the sex and age were not recorded. Among the GSE90277 dataset cases, there were $76(59.375 \%)$ males and $52(40.625 \%)$ females, whose ages ranged from 27 to 79 years old $(58.56 \pm 12.53$ years old). Among the cases from the TCGA database, there were 47 (56.63\%) males and $36(43.37 \%)$ females included, and the age range was from 33 to 90 years old $(64.18 \pm 11.62$ years old); for 1 case, the sex and age were not recorded. The cases with incomplete information were excluded.

\section{Screening of DEGs in each dataset}

After an integrated analysis of the GSE87211 and GSE90277 microarray data using R language, 256 normal tissue samples and 235 rectal cancer tissue samples were included in this study. After filtering according to the cutoff criteria of $\mid \log 2 \mathrm{FCl}>1$ and $\mathrm{P}$ value $<0.05,2,897$ DEGs were identified in the GSE87211 dataset, including 1,398 upregulated and 1,499 downregulated genes, while there were 2,803 DEGs in GSE90277 dataset, including 1,404 upregulated and 1,399 downregulated genes. The distribution of statistical parameters of different genes in the 2 datasets is shown in separate volcano plots (Figure 1A,B).

\section{Identification of robust DEGs}

The RRA method can be applied for effective integration of different datasets and can minimize bias and errors among them. Through this approach, as screened using the same cut-off criteria as those for DEGs, 137 robust DEGs were distinguished, including 49 upregulated and 88 downregulated genes. The specific information of all robust DEGs is listed in Table S1, and among them the top 20 upregulated and downregulated ones are visualized in the heatmap (Figure 1C). A consistent change trend of the same genes in different datasets can be observed.

\section{Functional analysis of robust DEGs}

The functions of the screened robust DEGs were further explored through GO enrichment and KEGG pathway enrichment analyses. The GO enrichment results revealed that the robust DEGs were mainly enriched in MFs of receptor ligand activity, signaling receptor activator activity and carbonate dehydratase activity; the most significant BPs were bicarbonate transport, chloride transport and antimicrobial humoral response; the most significant CCs included the apical part of cell, apical plasma membrane and zymogen granule (Figure $2 A$, Table S2). The KEGG pathway enrichment analysis indicated that the top 5 pathways through which the robust DEGs regulated the rectal cancer were: nitrogen metabolism, proximal tubule bicarbonate reclamation, cytokine-cytokine receptor interaction, pyruvate metabolism, and pancreatic secretion (Figure 2B, Table S3).

\section{Construction of the PPI Network}

The PPI interaction network of the robust DEGs was constructed using the STRING database and visualized with Cytoscape 3.6.0. There were 86 nodes and 156 edges, with 34 upregulated and 52 downregulated genes, after the removal of the disconnected nodes (Figure $3 A$ ). The whole PPI network was modularized into 5 key parts using the MCODE plugin; the scores of modules 1, 2, 3, 4 and 

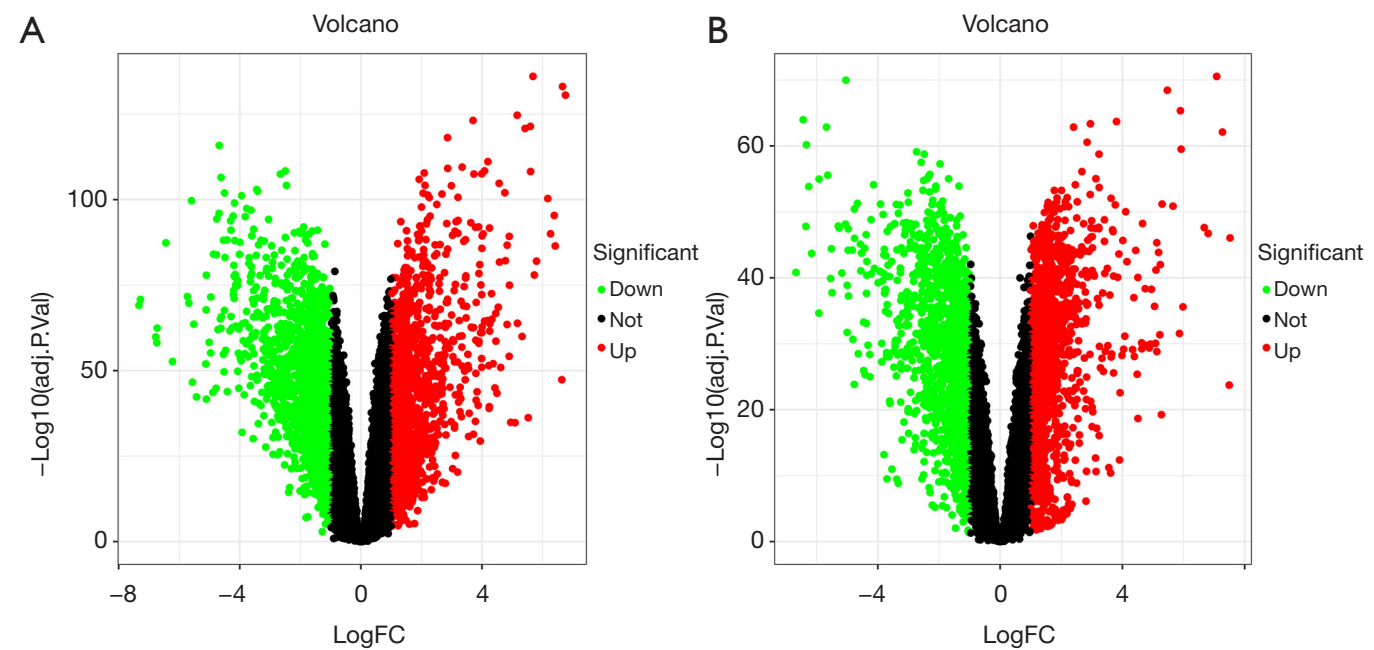

C

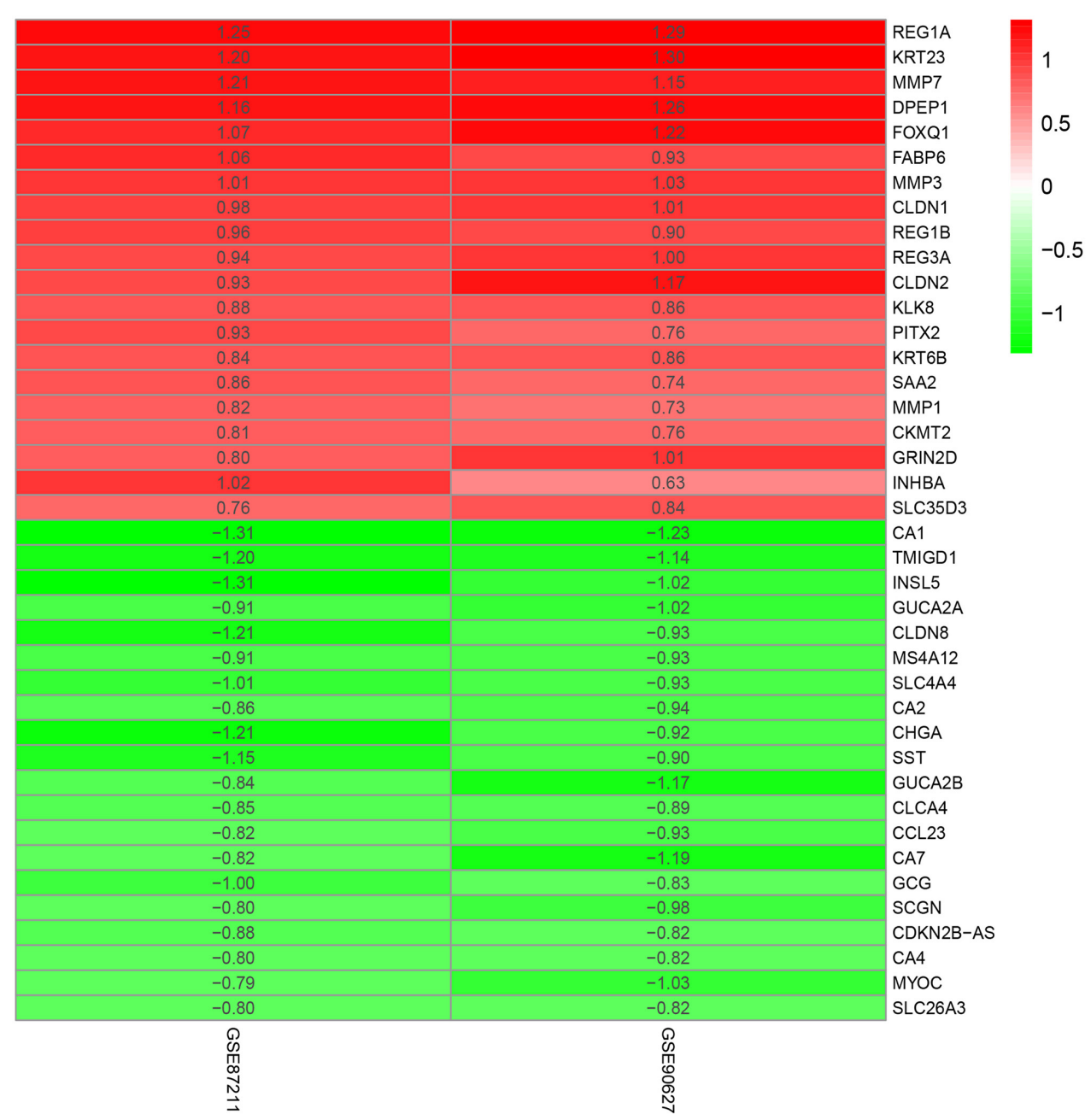

Figure 1 DEGs of selected datasets. (A) Volcano plots of DEGs in GSE87211. (B) Volcano plots of DEGs in GSE90627. (C) Heatmap of the top 20 upregulated and downregulated DEGs. Red represents upregulated DEGs, while green represents downregulated DEGs. DEG, differentially expressed gene. 
A

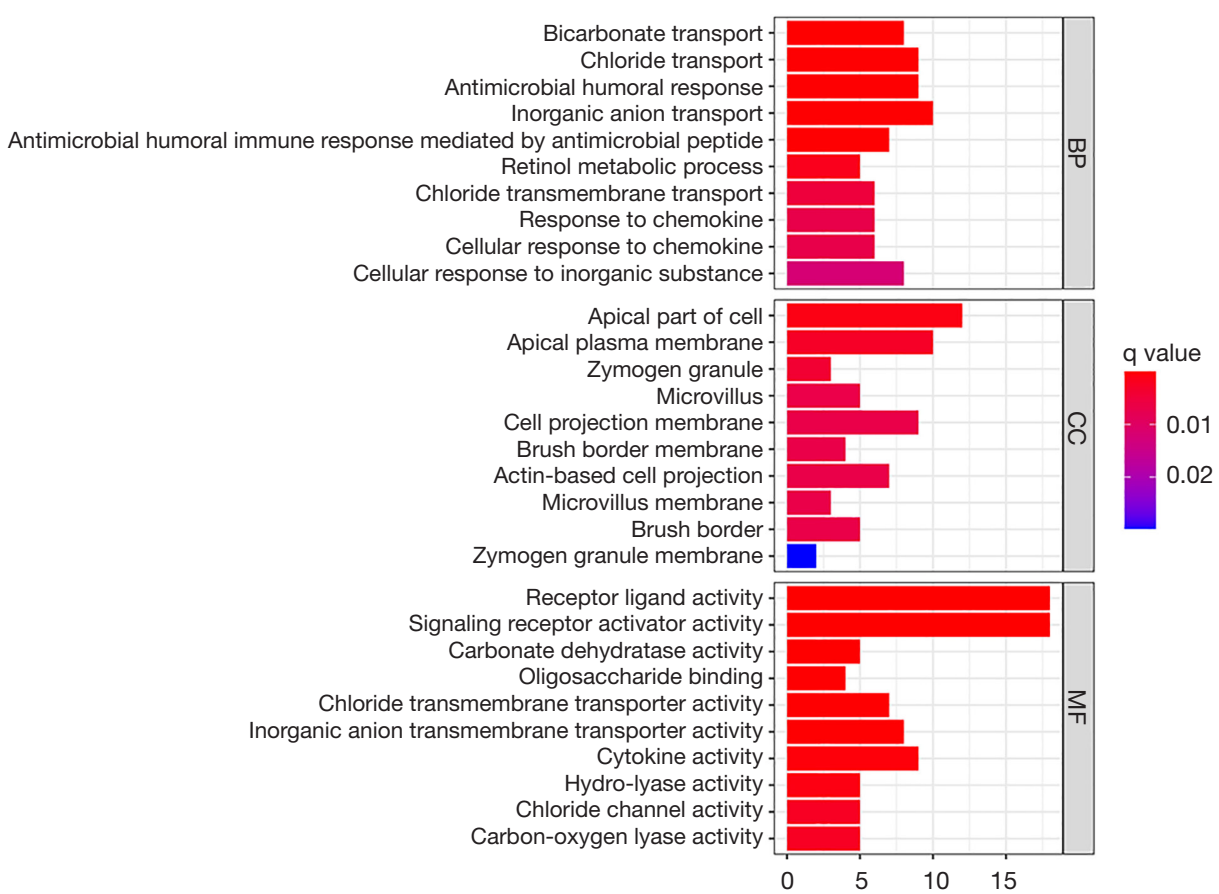

B

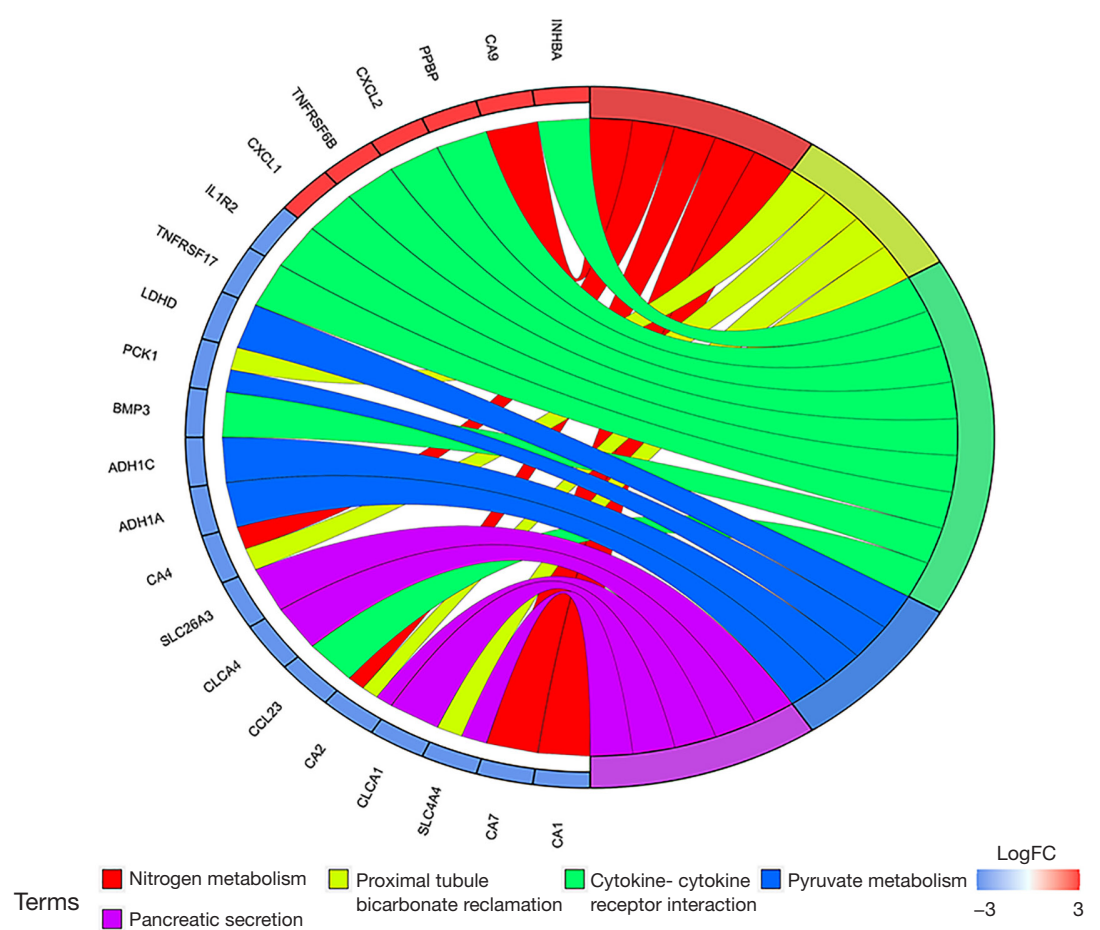

Figure 2 DEG functional enrichment analysis. (A) Bar plot of GO enrichment analysis of DEGs. (B) Circle graph of KEGG pathway analysis of DEGs. DEG, differentially expressed gene; GO, Gene Ontology; BP, biological process; CC, cellular component; MF, molecular function; KEGG, Kyoto Encyclopedia of Genes and Genomes. 
5 were $7.429,6,4,3.333$ and 3, respectively. According to the enrichment analyses of GO and KEGG (Tables S2,S3), module 1 was mainly related to the pancreatic secretion pathway (Figure 3B); module 2 was mainly related to the cytokine-cytokine receptor interaction pathway (Figure 3C); module 3 was mainly related to the BPs of antimicrobial humoral response and humoral immune response and the MFs of peptidoglycan binding and oligosaccharide binding (Figure 3D); module 4 was mainly related to the $\mathrm{BP}$ of the collagen catabolic process and the MFs of metallopeptidase activity and serine-type endopeptidase activity (Figure $3 E$ ); and module 5 was related to the BP of calcium-independent cell-cell adhesion via plasma membrane cell-adhesion molecules (Figure 3F).

\section{Hub gene identification}

To comprehensively analyze the hub genes in the PPI network, the scores of 10 topological parameters were integrated using the Cytoscape 3.6.0 cytoHubba plugin. The top 50 genes according to each algorithm were ranked, and the intersection of the ranked genes of 10 algorithms were taken and exhibited as UpSet diagram in order to obtain the hub genes. Finally, 24 common genes were identified as hub genes (Figure $3 G$ ). The detailed information of the 24 hub genes is given in Table 1 .

\section{Diagnostic and prognostic value of hub genes}

The expression distribution of the 24 hub genes in normal and rectal cancer tissue samples is illustrated as a boxplot (Figure 4A). Significant differences in these genes existed between the 2 tissue groups. GO terms for the BPs of the 24 hub genes were concentrated in the migration and chemotaxis of leukocytes and neutrophils, while the main rectal cancer-related KEGG pathways were the interleukin (IL)-17 signaling pathway and proximal tubule bicarbonate reclamation (Figure 4B,C, Tables S4,S5). The other functions of the hub genes were similar to those of the robust DEGs.

Correlation analysis revealed that all the hub genes were related to each other (Figure $5 A$ ). ROC curve analysis by $\mathrm{R}$ package indicated that all 24 hub genes had a high diagnostic value for identifying rectal cancer: GUCA2B (full name of genes were listed in Table 1) area under the curve (AUC) $=0.970$, GUCA2A AUC $=0.965$, TMIGD1 AUC $=0.966$, SLC26A3 AUC $=0.945$, MS4A12 AUC $=0.938$, SPP1 AUC $=0.910$, PPBP AUC $=0.911$, CLCA4 AUC $=0.919$, SI AUC
$=0.855$, CLCA 1 AUC $=0.860$, SST AUC $=0.955$, CXCL2 AUC $=0.936$, SAA 1 AUC $=0.928$, CXCL1 AUC $=0.948$, AQP8 AUC $=0.954$, MMP1 AUC $=0.927$, COL1A1 AUC $=0.909$, SLC4A4 AUC $=0.975$, SLC30A10 AUC $=0.946$, PCK1 AUC $=0.927$, TGFBI AUC $=0.955$, TTR AUC $=0.880$, CHGA AUC $=0.941$, and GCG AUC $=0.947$ (Figure 5B).

The prognostic value of hub genes was verified using the TCGA database. READ tissue samples in the TCGA dataset were divided into groups with high and low expression of hub genes according to the best-separation cutoff value, Kaplan-Meier (K-M) survival curves, and the correlation between hub genes and overall survival (OS) were analyzed using $\mathrm{R}$ package. The hub DEGs SAA1 $(\mathrm{P}=0.036)$, SPP1 $(\mathrm{P}=0.001)$, SI $(\mathrm{P}=0.02)$, CLCA1 $(\mathrm{P}=0.039)$, AQP8 $(\mathrm{P}=0.018)$, COLIA1 $(\mathrm{P}=0.025)$, MMP1 $(\mathrm{P}=0.016)$, and TGFBI $(\mathrm{P}=0.01)$ were found to be significantly associated with $\mathrm{OS}$ in the READ population. However, only the correlations of SAA1, SPP1, SI, and CLCA1with prognosis were consistent with the clinical significance of gene overexpression (Figure 6); the correlations between AQP8, COLIA1, MMP1, and TGFBI and prognosis were not in accordance with the clinical significance of gene overexpression (Figure S1). The diagnostic and prognostic value of CLCA1 in colon cancer and rectal cancer has been reported previously.

\section{Analysis of immune cell infiltration}

The 22 types of infiltrated immune cells in normal tissues and rectal cancer tissues were analyzed using the CIBERSORT algorithm. The distribution of the 22 types of immune cells in each sample showed there to be immunological differences between normal and rectal cancer tissue samples (Figure 7A). The abundance of immune cells in each sample is illustrated as a heatmap in Figure $7 B$, and the violin plot in Figure $7 C$ visualizes the differences in each type of immune cell between the 2 groups. Compared with normal tissue samples, rectal cancer tissue samples displayed significantly increased abundance of T cells CD4 naive, T cells CD4 memory activated, natural killer (NK) cells resting, monocytes, macrophages $\mathrm{M} 0$, dendritic cells activated, mast cells activated, and neutrophils. Immune cells with significantly reduced abundance levels included B cells memory, plasma cells, T cells CD8, T cells CD4 memory resting, T cells follicular helper, macrophages M2, and mast cells resting. Immune cells such as B cells naive, $\mathrm{T}$ cells regulatory (Tregs), $\mathrm{T}$ cells gamma delta, NK cells activated, macrophages M1, dendritic cells resting, and eosinophils showed no difference between the 2 groups. 


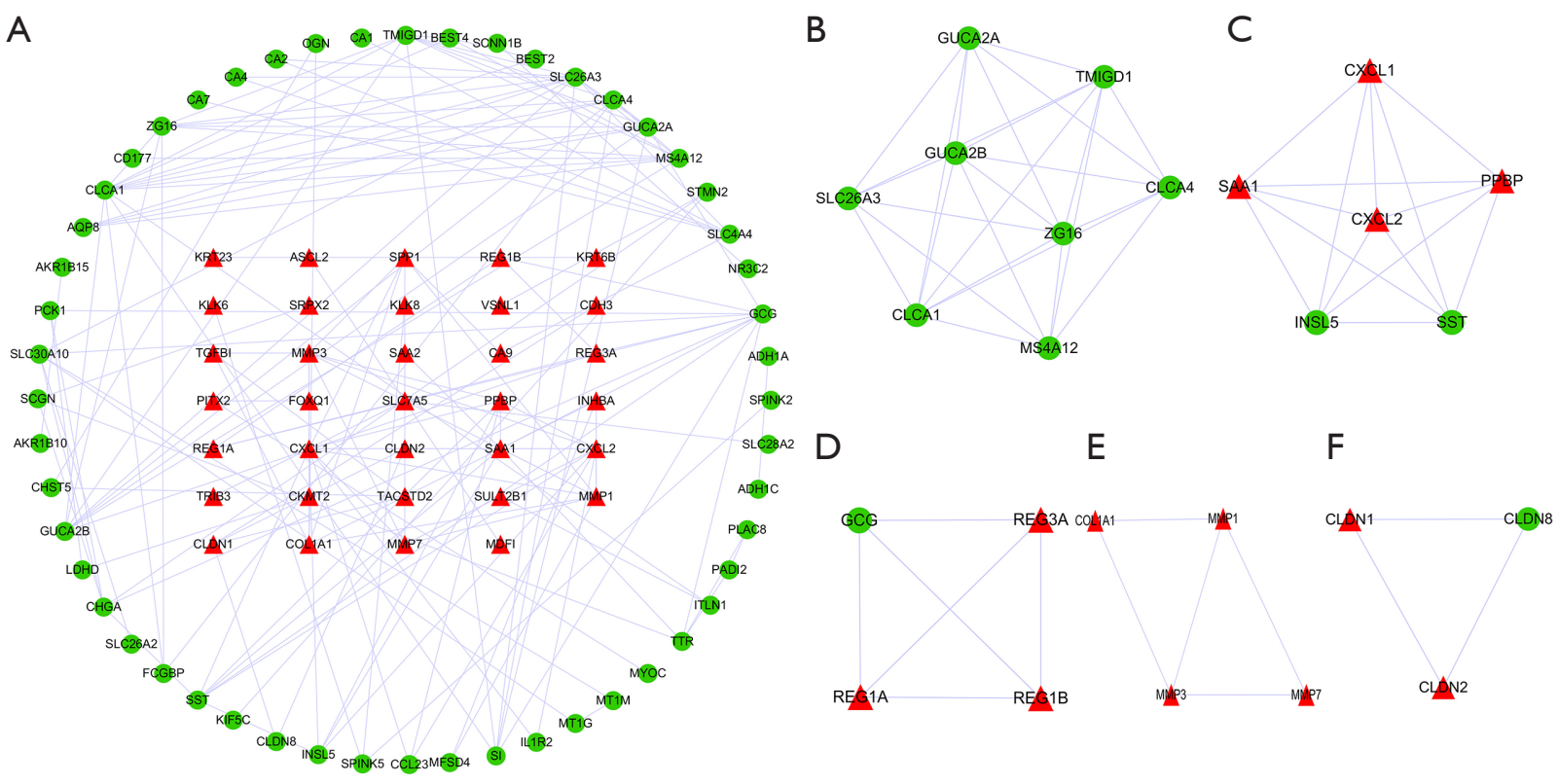

G

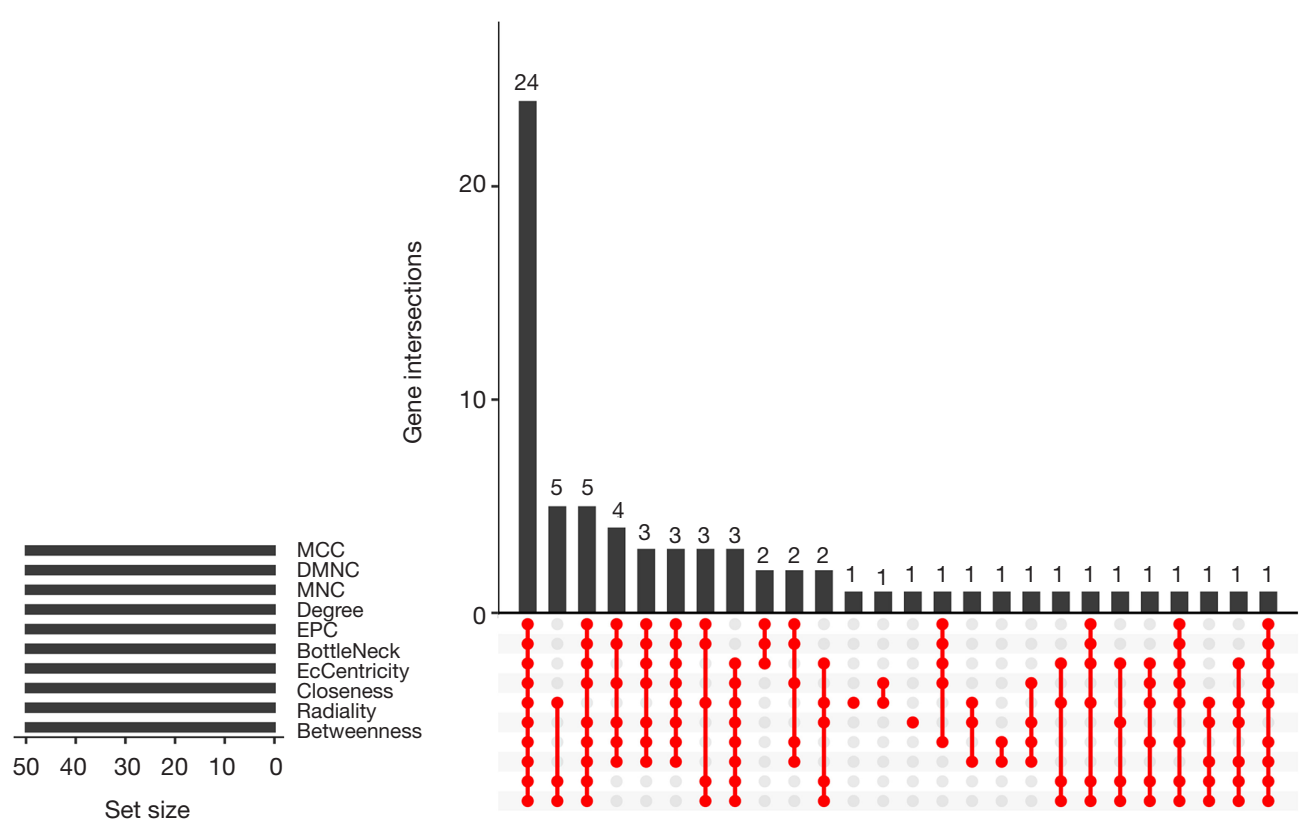

Figure 3 PPI network and hub genes. (A) PPI network of the DEGs. PPI network was divided into different modules: (B) module 1, (C) module 2, (D) module 3, (E) module 4, (F) module 5. (G) Hub genes were identified by intersecting the top 50 genes of every algorithm. Red triangles represent upregulated genes, while green circles represent downregulated genes. PPI, protein-protein interaction; DEG, differentially expressed gene.

The 15 differentially expressed immune cells may be closely related to rectal cancer occurrence and development. The PCA results of immune cell infiltration implied that there were differences between the normal and rectal cancer tissue groups, although in some individual samples, no difference was found between the 2 groups (Figure 7D).

Correlation analysis showed that 12 of the 15 infiltrated immune cells were related to each other, with the exception of $\mathrm{T}$ cells follicular helper, NK cells resting, and dendritic cells activated (Figure 8A). The sensitivity and specificity of these 15 differential 
Table 1 Description of the 24 hub genes

\begin{tabular}{|c|c|c|}
\hline Gene & Full name & Change \\
\hline GUCA2B & Guanylate cyclase activator 2B & Down \\
\hline TMIGD1 & Transmembrane and immunoglobulin domain-containing protein 1 & Down \\
\hline SLC26A3 & Chloride anion exchanger & Down \\
\hline MS4A12 & Membrane-spanning 4-domains subfamily A member 12 & Down \\
\hline SPP1 & Osteopontin & Up \\
\hline PPBP & Platelet basic protein & Up \\
\hline GUCA2A & Guanylin & Down \\
\hline CLCA4 & Calcium-activated chloride channel regulator 4 & Down \\
\hline SI & Sucrase-isomaltase, intestinal & Down \\
\hline CLCA1 & Calcium-activated chloride channel regulator 1 & Down \\
\hline SST & Somatostatin & Down \\
\hline CXCL2 & C-X-C motif chemokine 2 & Up \\
\hline SAA1 & Serum amyloid A-1 protein & Up \\
\hline CXCL1 & Growth-regulated alpha protein & Up \\
\hline AQP8 & Aquaporin-8 & Down \\
\hline MMP1 & Interstitial collagenase & Up \\
\hline COL1A1 & Collagen alpha-1(I) chain & Up \\
\hline SLC4A4 & Electrogenic sodium bicarbonate cotransporter 1 & Down \\
\hline SLC30A10 & Zinc transporter 10 & Down \\
\hline PCK1 & Phosphoenolpyruvate carboxykinase, cytosolic (GTP) & Down \\
\hline TGFBI & Transforming growth factor-beta-induced protein ig-h3 & Up \\
\hline$T T R$ & Transthyretin & Down \\
\hline CHGA & Chromogranin-A & Down \\
\hline GCG & Glucagon & Down \\
\hline
\end{tabular}

immune cells for the diagnosis of rectal cancer were further verified by ROC curve analysis (Figure $8 B$ ). The results showed that except for $\mathrm{T}$ cells follicular helper (AUC $=0.422$ ), NK cells resting (AUC $=0.551$ ), and dendritic cells activated (AUC $=0.621)$, the other 12 types of infiltrated immune cells were all sensitive for the identification of rectal cancer, with AUCs $>0.65$. Therefore, the characteristics of immune cell infiltration maybe an effective indicator of rectal cancer.

\section{Relationship between prognostic genes and immune cell infiltration}

The relationship between prognostic genes and immune infiltration in rectal cancer was further analyzed. According to relationship evaluation criteria, SAA1 exhibited a strong correlation with macrophages $\mathrm{M} 0$, mast cells resting, and macrophages M2; a moderate correlation with $\mathrm{T}$ cells CD4 memory activated, plasma cells, T cells CD4 memory resting, neutrophils, mast cells activated, T cells CD4 naive, and $\mathrm{T}$ cells $\mathrm{CD} 8$; and a weak correlation with B cells memory and monocytes. SPP1 exhibited a strong correlation with macrophages M0 and M2, mast cells resting, and mast cells activated; a moderate correlation with T cells CD4 memory resting, neutrophils, plasma cells, T cells CD4 naive, T cells CD8, and B cells memory; and a weak correlation with $\mathrm{T}$ cells CD4 memory activated and monocytes. SI exhibited a 
A

Type 追 Normal 追 Tumor

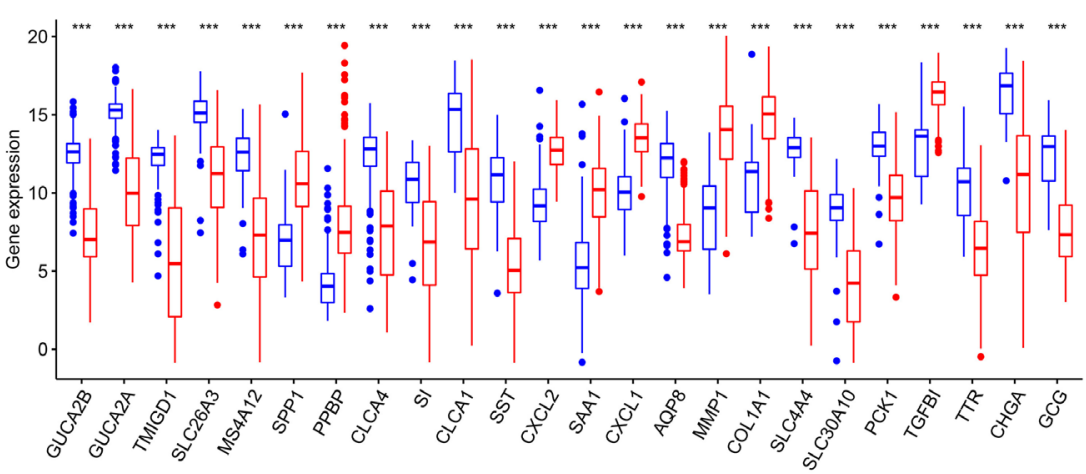

B

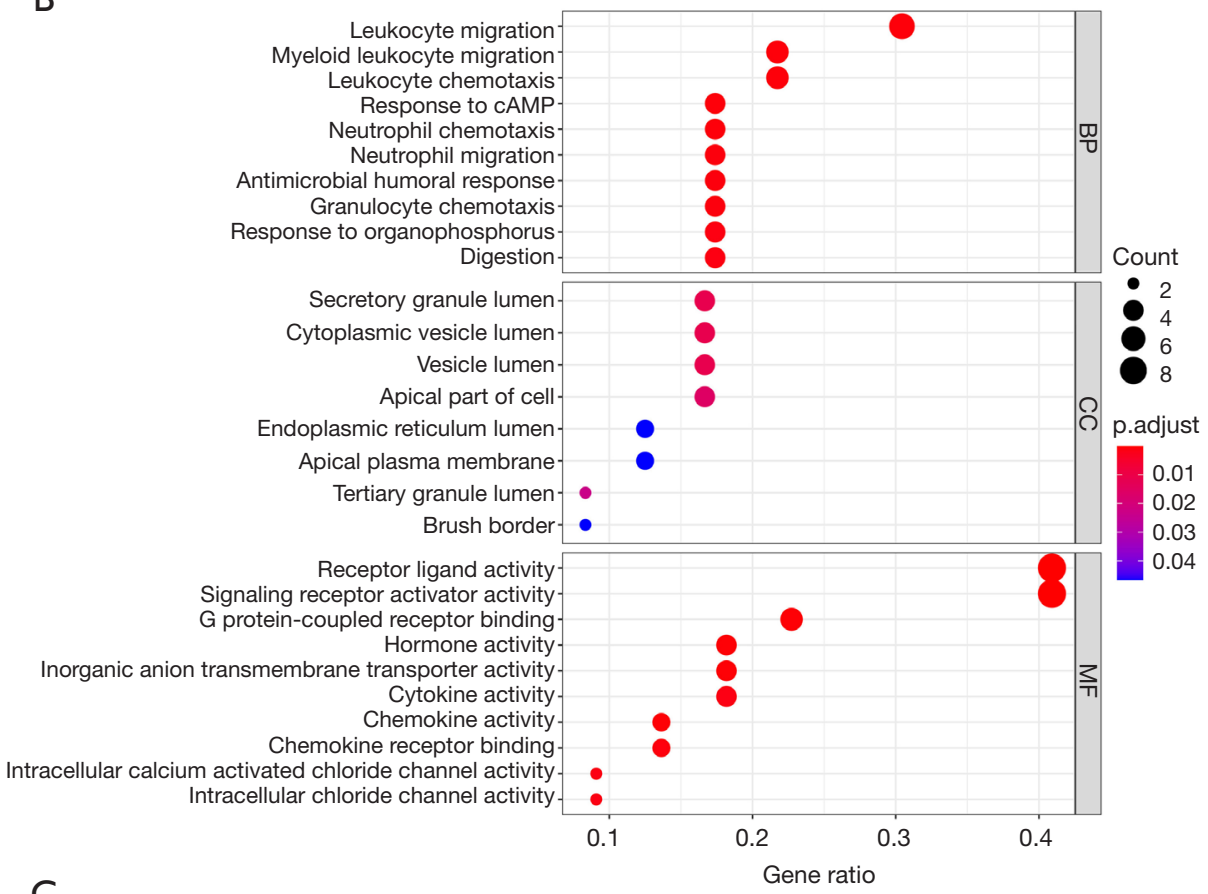

C

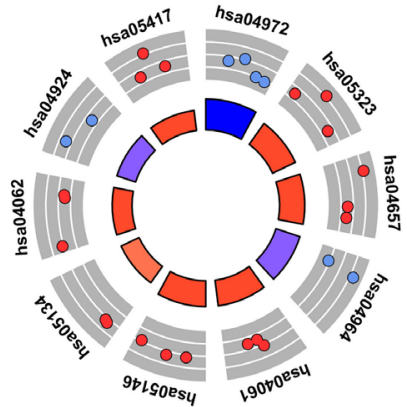

LogFC

\begin{tabular}{|c|c|}
\hline ID & $\begin{array}{c}\text { Description } \\
\text { hsa04972 }\end{array}$ \\
\hline hsa05323 & Rhereatic secretion \\
\hline hsa04657 & IL-17 signaling pathway \\
\hline hsa04964 & Proximal tubule bicarbonate reclamation \\
\hline hsa04061 & Viral protein interaction with cytokine and cytokine receptor \\
\hline hsa05146 & Amoebiasis \\
\hline hsa05134 & Legionellosis \\
\hline hsa04062 & Chemokine signaling pathway \\
\hline hsa04924 & Renin secretion \\
\hline hsa05417 & Lipid and atherosclerosis \\
\hline
\end{tabular}

Z-score

- Downregulated - Upregulated

$$
\text { Decreasing Increasing }
$$

Figure 4 Expression and function of hub genes. (A) Expression of 24 hub genes. (B) Bubble chart of GO enrichment analysis. (C) Circle graph of KEGG pathway enrichment analysis. GO, Gene Ontology; KEGG, Kyoto Encyclopedia of Genes and Genomes. 
A

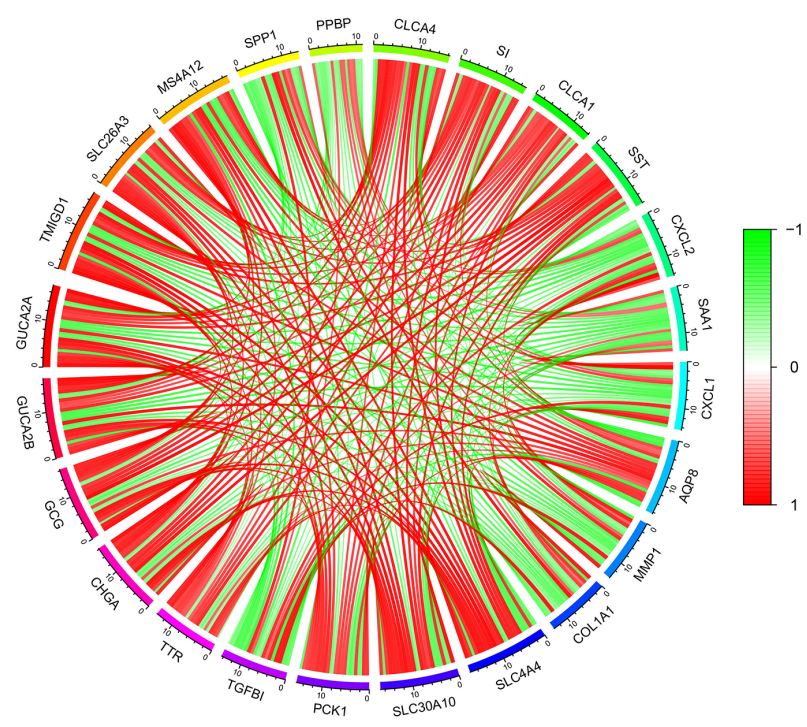

B

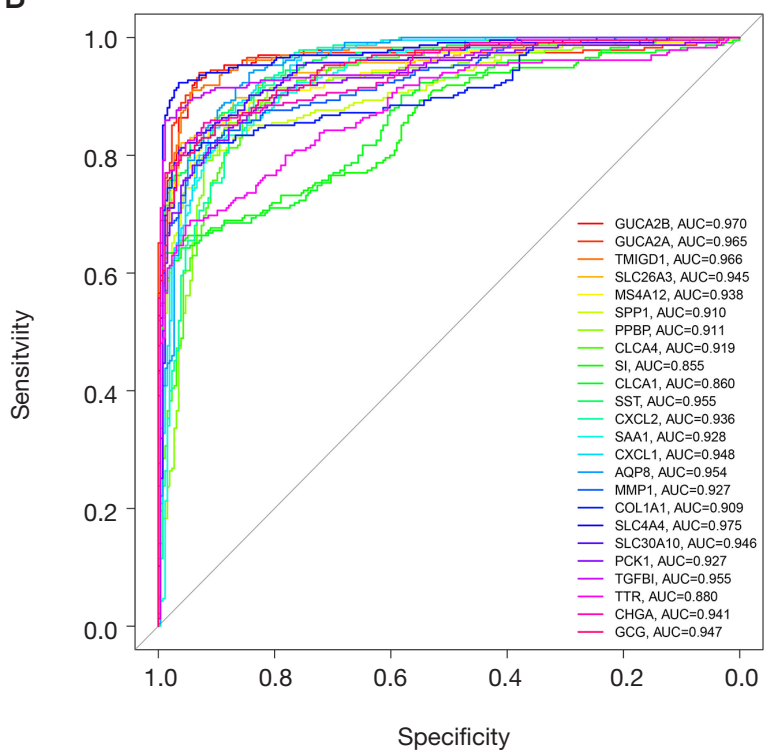

Figure 5 Evaluation of diagnostic value of hub genes. (A) Correlations exist between each other of the 24 hub genes. (B) ROC curves of the 24 hub genes. ROC, receiver operating characteristic.

strong correlation with macrophages $\mathrm{M} 2$, neutrophils, and plasma cells; a moderate correlation with mast cells resting, T cells CD4 memory resting, B cells memory, macrophages M0, T cells CD4 naive, mast cells activated, and T cells CD8; and a weak correlation with T cells CD4 memory activated and monocytes (Figure 9). CLCA1 also exhibited correlations with the 12 types of infiltrated immune cells (Figure S2).

\section{Discussion}

Due to the complexity of pathogenesis and heterogeneity of cancer, the use of a single biomarker is not reliable or suitable for diagnosing or prognosticating the disease. It is necessary to integrate multiple biomarkers or assessment indices to obtain a more accurate indicator of cancer. Open public data platforms such as GEO and TCGA provide an opportunity for the discovery and validation of tumor biomarkers. For instance, a study in China showed that tissue expression of myc proto-oncogene protein (MYC), proliferating cell nuclear antigen (PCNA), and Metalloproteinase inhibitor 1 (TIMP1) protein combining with MRI-detected extramural vascular invasion could provide additional prognostic details for the preoperative treatment of rectal cancer (7). Another study, also from China, integrated 3 GEO microarray datasets to analyze gene biomarkers of CRC. In the present work, the included
2 microarray datasets of rectal cancer from different countries, each of which had a minimum sample size of 32 , which may be helpful in reducing the deviation caused by racial, regional, and individual differences in biomarker research. The same upward or downward trend for each gene in the 2 datasets suggested the reliability of the results.

The 137 robust DEGs including 49 upregulated genes and 88 downregulated genes were identified using a standard and robust RRA method, and 24 hub genes were further obtained. Analyses of GO enrichment and KEGG pathway indicated that the DEGs were mainly involved in bicarbonate transport and material metabolism-related BPs, MFs and signaling pathways. Besides, hub genes mainly took part in proximal tubule bicarbonate reclamation and the IL-17 signaling pathway. Previous studies have shown that the transport of bicarbonate plays an important role in the diagnosis and treatment of multiple cancers, and the expression levels of bicarbonate transporter in patients with colon cancer have changed widely compared with that in healthy bodies. The results of this work confirm that bicarbonate transport also plays an important role in rectal cancer.

In the PPI network, 24 hub genes were discovered through the integration of 10 algorithms to improve the accuracy. GUCA2B binding with GUCA2A can trigger the activation of a transmembrane receptor expressed on intestinal epithelial cells, guanylyl cyclase C (GUCY2C), 
A
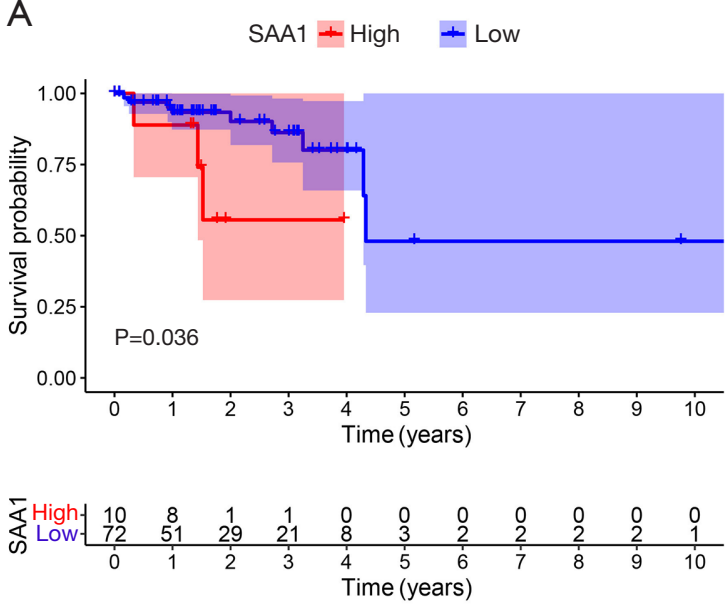

C
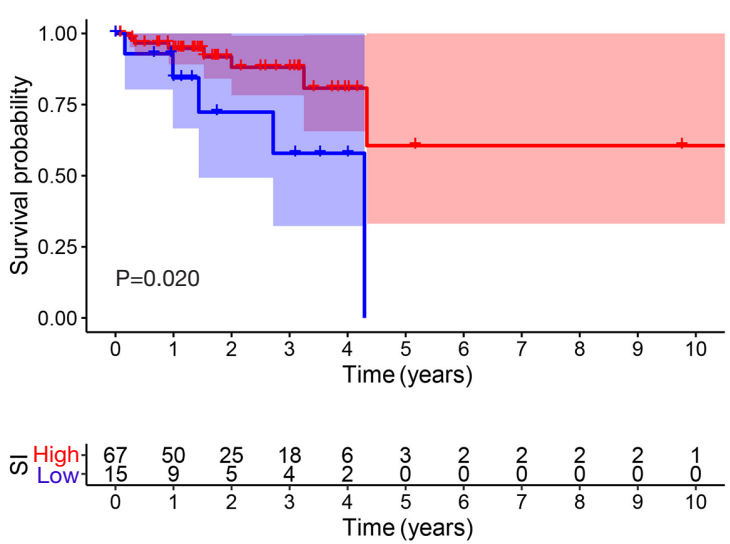

B
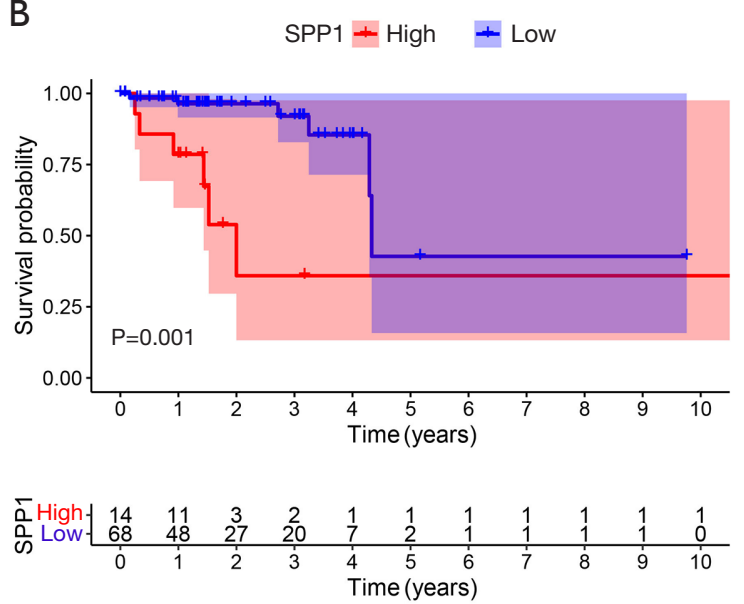

D $\quad \mathrm{CLCA} 1+$ High + Low
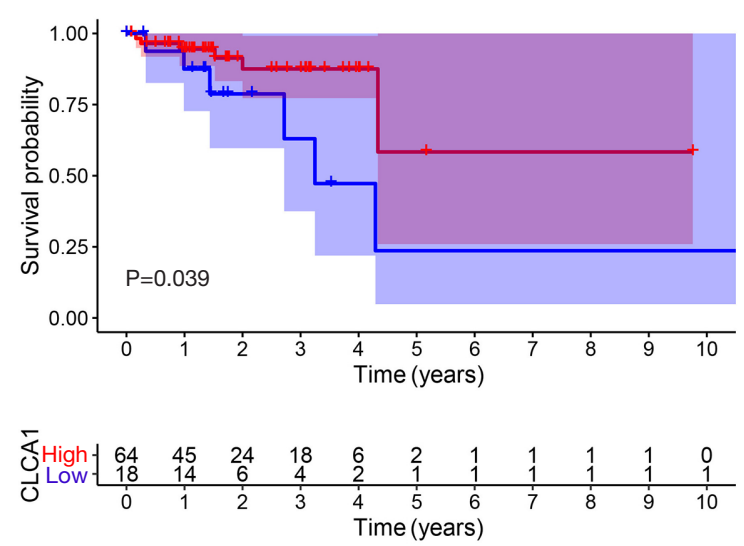

Figure 6 Survival analysis of the 24 hub genes. Gene changes of SAA1 (A), SPP1 (B), SI (C), and CLCA1 (D) were obviously associated with the overall survival of patients with rectal cancer $(\mathrm{P}<0.05)$.

which participates in regulatory mechanism of intestinal homeostasis, and its deletion may be related to the occurrence of CRC $(15,16)$. Downregulation of GUCA2B and GUCA2A confirmed their important roles in rectal cancer development. In renal cancer, TMIGD1 is a tumor suppressor via regulation of $\mathrm{p} 21 \mathrm{Cip} 1 / \mathrm{p} 27 \mathrm{Kip} 1$, but its relationship with other cancers is unclear (17). Attention has increasingly been paid to the role of plasma membrane transporters in cancer; for instance, the representative SLC26A3 is a tumor suppressor for colon cancer. As a $\mathrm{Cl}^{-} /$ $\mathrm{HCO}^{-}$exchanger, SLC26A3 can promote the outflow of $\mathrm{HCO}^{-}$and possibly play an anti-tumor effect through the regulation of intracellular $\mathrm{pH}$ (18). As a member of the membrane-spanning 4-domains subfamily, MS4A12 is specifically expressed in colon epithelium, which can affect the colon cancer cell proliferation and cell cycle, and is a potential target for colon cancer immunotherapy (19). The calcium-activated chloride channel protein CLCA4 and the cyclic tetradeca peptide hormone SST can inhibit the proliferation and invasion of CRCs $(20,21)$. SI deficiency can lead to dyspepsia, but its correlation with CRC is unclear (22). The calcium-activated chloride channel protein CLCA1 has been proposed as a diagnostic and prognostic biomarker for both colon and rectal cancer (23). Over expression of AQP8, a member of aquaporins family, can inhibit the proliferation and invasion of colon cancer cells (24). The decreased expression of CHGA in the early stage of colon cancer may be a novel biomarker for colon cancer diagnosis (25). Downregulated SLC4A4 can suppress progression of CRC (26). The relationship between TTR, 


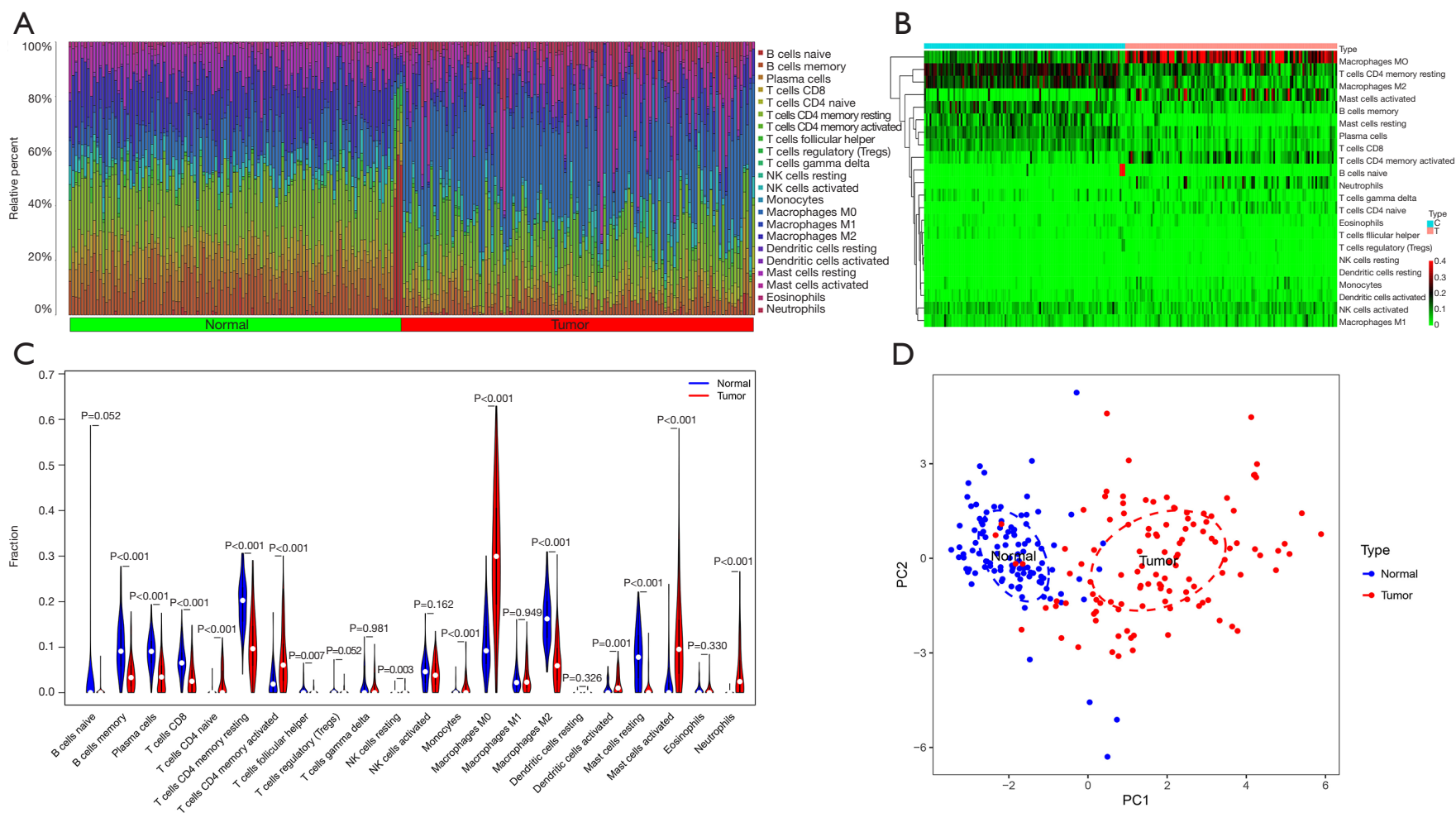

Figure 7 Immune cell infiltration characteristics. (A) Accumulation percentage histogram of the infiltrated immune cells distribution in normal and rectal cancer tissues. (B) Heatmap showing the abundance of immune cells in all samples. (C) Violin plot of the difference in each type of immune cell between normal and rectal cancer tissues $(\mathrm{P}<0.05)$. (D) PCA performed on normal and rectal cancer tissues. PCA, principal component analysis.

A

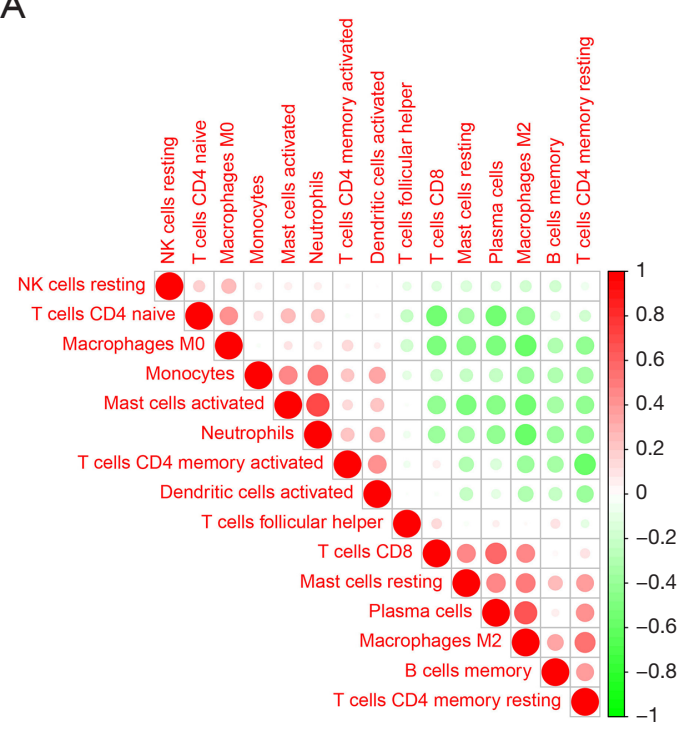

B

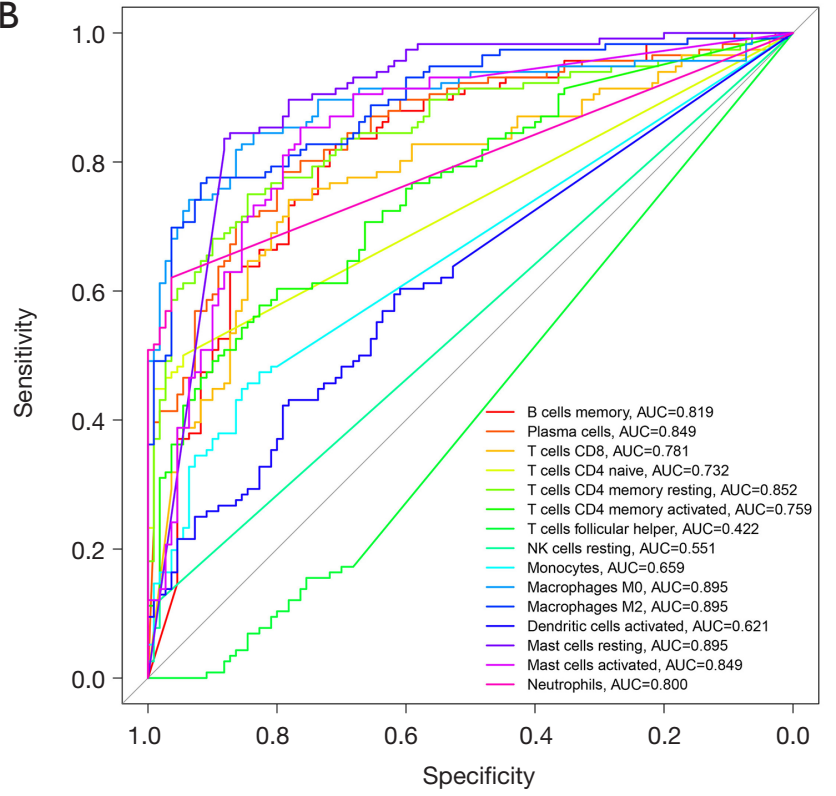

Figure 8 Diagnostic value of infiltrated immune cells. (A) Correlation between each of the infiltrated immune cell types. (B) ROC curves of infiltrated immune cells. ROC, receiver operating characteristic. 

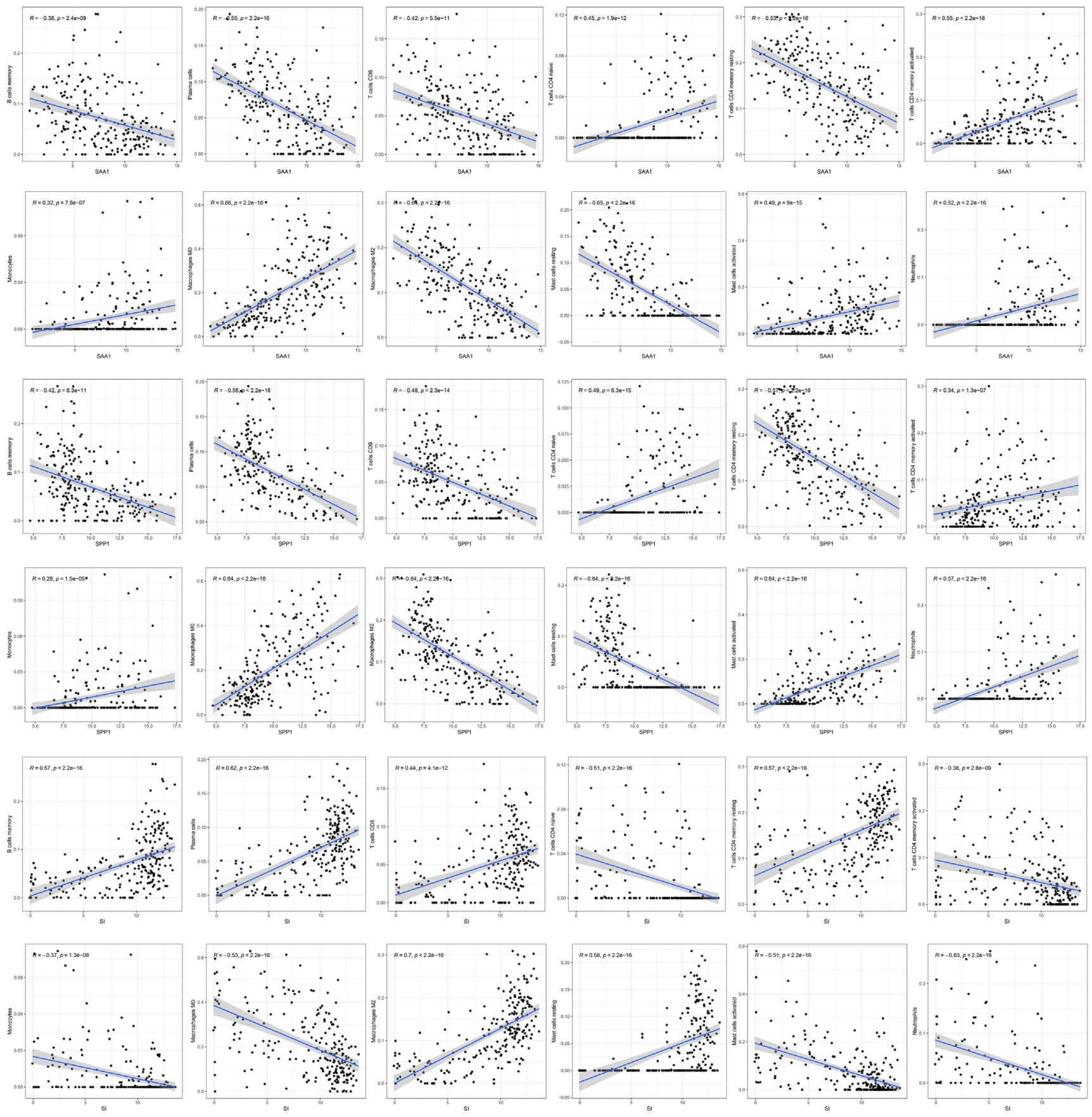

Figure 9 Relationship between the prognostic genes of $S A A 1$, SPP1, and SI, and immune infiltration.

GCG, and CRC has not yet been illuminated. A singlechip-based study identified PPBP as the core gene of rectal cancer (27). Chemokine (C-X-C motif) ligands including CXCL1 and CXCL2 are the only diagnostic and prognostic biomarkers for colon cancer (28). SPP1 is related to a poor prognosis of colon cancer, and MMP1 is related to a poor prognosis of CRC $(20,29)$. SAA1 can promote breast cancer metastasis via immune cell infiltration, and it is highly expressed in colon cancer as well as TGFBI (30-32). The effects of downregulation or upregulation of 
the above genes demonstrate that they also play a major role in the development of rectal cancer. Additionally, COL1A1, SLC30A10, and PCK1 can promote CRC metastasis via regulation of the WNT/PCP pathway, the miR-21c/APC axis, and nucleotide synthesis (33-35). Furthermore, the expression levels of cancer promoting SLC30A10 and PCK1 were decreased in rectal cancer samples based on the 2 GEO datasets, which needs to be further verified. In brief, GUCA2B, GUCA2A, TMIGD1, SLC26A3, MS4A12, CLCA4, SST, SI, CLCA1, AQP8, SLC4A4, GCG, CXCL1, and SLC30A10 which have been reported to be diagnostic biomarkers in CRC by other microarray dataset studies, PPBP and CXCL2 which were found to be biomarkers of rectal cancer in a single microarray dataset study, and CHGA, TTR, SAA1, SPP1, MMP1, TGFBI, COL1A1, and PCK1, may constitute a gene biomarker group for the identification of rectal cancer.

The correlation analysis between these gene markers and survival time based on the TCGA database showed that 8 genes were significantly correlated with survival time $(\mathrm{P}<0.05)$. Among them, high expression levels of SAA1 and SPP1 are associated with a poor prognosis, while high expression levels of SI and CLCA1 are associated with an improved prognosis of rectal cancer, and the prognostic significance of CLCA1 has also been evidenced by research of other datasets, thus confirming the reliability of the study (23). For AQP8, MMP1, COL1A1, and TGFBI, the relationship between genes and prognosis is not consistent with the clinical significance of gene overexpression, which needs to be further verified using a larger sample. Thus, SAA1, SPP1, and SI could be new prognostic biomarkers of rectal cancer.

A variety of treatment methods based on immune classification exhibit certain advantages against cancer. Tumor immune infiltrating can directly or indirectly interfere with the progress of tumor through the release of cytokines or cytokine receptors and interaction with other components in the TME (36). The prognostic value of different immune cells depends on the type of cancer, and the type and abundance of infiltrated immune cells are important factors for tumor immune infiltration affecting the clinical prognosis. An understanding of the characteristics of immune cells and the body's immune state is helpful for evaluating the pathological status or therapeutic effects. Analysis of the distribution of the 22 types of infiltrated immune cells using the CIBERSORT algorithm showed that 15 types of immune cells differed significantly between normal and rectal cancer tissues, including 1 type of B lymphocyte, 1 type of plasma cell, 5 types of T lymphocytes, 1 type of NK cell, 1 type of monocyte,
2 types of macrophages, 1 type of dendritic cell, 2 types of mast cells, and neutrophils. Previous studies have shown that Tregs have both positive and negative effects in CRC, which may depend on the location of invasion and the definition of "Tregs" used (37). However, there was no difference of Tregs in this study, which may be related to the above factors, or the region, race and number of samples. The increased abundance of T cells CD4 naive, T cells CD4 memory activated, NK cells resting, monocytes, macrophages M0, dendritic cells activated, mast cells activated, and neutrophils implies that these cells may be positively correlated with rectal cancer, whereas the decreased abundance of B cells memory, plasma cells, T cells CD8, T cells CD4 memory resting, $\mathrm{T}$ cells follicular helper, macrophages $\mathrm{M} 2$, and mast cells resting implies that these cells may be negatively associated with rectal cancer. Among the 12 sensitive immune cells, the prognostic genes SAA1, SPP1, and SI all have the closest correlation with macrophages M2. As a reported diagnostic and prognostic signature of colon cancer and rectal cancer, CLCA1 is also closely correlated with the 12 immune cells. Other studies have shown that in CRC, infiltrated $\mathrm{T}$ helper 1 cells, $\mathrm{T}$ cells follicular helper, macrophages $\mathrm{M} 1$, dendritic cells, and NK cells are associated with a good prognosis, while macrophages M2, myeloid-derived suppressor cells, T helper 17 cells, and B cells are associated with a poor prognosis (38). Because features of rectal cancer may be not entirely identical to those of colon cancer, the correlation between these infiltrated immune cells and the prognosis of rectal cancer needs to be further studied.

In conclusion, a biomarker group of 24 differential genes integrating with immune cell infiltration characteristics was found to be conducive to obtaining a comprehensive reflection of the body state and effectively indicating rectal cancer. Functional enrichment analysis indicated that the hub genes were closely associated with the process of rectal cancer. Among them, SAA1, SPP1, and SI may be novel prognostic biomarkers of rectal cancer. Of course, due to the limitation resulting from sample sizes in the GEO and TCGA databases, validation of our results in clinical cohort studies based on multiple centers and a large sample size is needed in the future. This study may provide reference for early diagnosis and treatment monitoring of rectal cancer at molecular and immune levels.

\section{Acknowledgments}

Funding: This work was supported by National Natural Science Foundation of China (No. 81803773), Incubating 
Program of Beijing Municipal Administration of Hospitals (PX2020078), and Open Project of Beijing Key Laboratory of Urine Cell Molecular Diagnosis (No. 2020-KF18).

\section{Footnote}

Reporting Checklist: The authors have completed the REMARK and MDAR reporting checklist. Available at https://dx.doi.org/10.21037/jgo-21-255

Conflicts of Interest: Both authors have completed the ICMJE uniform disclosure form (available at https://dx.doi. org/10.21037/jgo-21-255). The authors have no conflicts of interest to declare.

Ethical Statement: The authors are responsible for all aspects of the work to ensure that issues relating to the accuracy or completeness of any part of the work are properly investigated and resolved. Since this was a retrospective database study based on a public database, approval from the ethics committee was not required. The study was conducted in accordance with the Declaration of Helsinki (as revised in 2013).

Open Access Statement: This is an Open Access article distributed in accordance with the Creative Commons Attribution-NonCommercial-NoDerivs 4.0 International License (CC BY-NC-ND 4.0), which permits the noncommercial replication and distribution of the article with the strict proviso that no changes or edits are made and the original work is properly cited (including links to both the formal publication through the relevant DOI and the license). See: https://creativecommons.org/licenses/by-nc-nd/4.0/.

\section{References}

1. Siegel RL, Miller KD, Goding Sauer A, et al. Colorectal cancer statistics, 2020. CA Cancer J Clin 2020;70:145-64.

2. Modest DP, Pant S, Sartore-Bianchi A. Treatment sequencing in metastatic colorectal cancer. Eur J Cancer 2019;109:70-83.

3. Piawah S, Venook AP. Targeted therapy for colorectal cancer metastases: A review of current methods of molecularly targeted therapy and the use of tumor biomarkers in the treatment of metastatic colorectal cancer. Cancer 2019;125:4139-47.

4. Vassos N, Piso P. Metastatic Colorectal Cancer to the Peritoneum: Current Treatment Options. Curr Treat Options Oncol 2018;19:49.
5. Jiao Q, Ren Y, Ariston Gabrie AN, et al. Advances of immune checkpoints in colorectal cancer treatment. Biomed Pharmacother 2020;123:109745.

6. Bailey CE, Hu CY, You YN, et al. Increasing disparities in the age-related incidences of colon and rectal cancers in the United States, 1975-2010. JAMA Surg 2015;150:17-22.

7. Dayde D, Tanaka I, Jain R, et al. Predictive and Prognostic Molecular Biomarkers for Response to Neoadjuvant Chemoradiation in Rectal Cancer. Int J Mol Sci 2017;18:573.

8. De Felice F, Crocetti D, Maiuri V, et al. Locally Advanced Rectal Cancer: Treatment Approach in Elderly Patients. Curr Treat Options Oncol 2020;21:1.

9. Oh HH, Joo YE. Novel biomarkers for the diagnosis and prognosis of colorectal cancer. Intest Res 2020;18:168-83.

10. Galon J, Angell HK, Bedognetti D, et al. The continuum of cancer immunosurveillance: prognostic, predictive, and mechanistic signatures. Immunity 2013;39:11-26.

11. Shen Y, Guan Y, Hummel JJ, et al. Immunogenomic pathways associated with cytotoxic lymphocyte infiltration and survival in colorectal cancer. BMC Cancer 2020;20:124.

12. Kolde R, Laur S, Adler P, et al. Robust rank aggregation for gene list integration and meta-analysis. Bioinformatics 2012;28:573-80.

13. Niu J, Yan T, Guo W, et al. Identification of Potential Therapeutic Targets and Immune Cell Infiltration Characteristics in Osteosarcoma Using Bioinformatics Strategy. Front Oncol 2020;10:1628.

14. Chin $\mathrm{CH}$, Chen $\mathrm{SH}, \mathrm{Wu} \mathrm{HH}$, et al. cytoHubba: identifying hub objects and sub-networks from complex interactome. BMC Syst Biol 2014;8 Suppl 4:S11.

15. Xu H, Ma Y, Zhang J, et al. Identification and Verification of Core Genes in Colorectal Cancer. Biomed Res Int 2020;2020:8082697.

16. Pattison AM, Merlino DJ, Blomain ES, et al. Guanylyl cyclase $\mathrm{C}$ signaling axis and colon cancer prevention. World $\mathrm{J}$ Gastroenterol 2016;22:8070-7.

17. Meyer RD, Zou X, Ali M, et al. TMIGD1 acts as a tumor suppressor through regulation of p21Cip1/p27Kip1 in renal cancer. Oncotarget 2018;9:9672-84.

18. Bhutia YD, Babu E, Ramachandran S, et al. SLC transporters as a novel class of tumour suppressors: identity, function and molecular mechanisms. Biochem J 2016;473:1113-24.

19. Koslowski M, Sahin U, Dhaene K, et al. MS4A12 is a colonselective store-operated calcium channel promoting malignant cell processes. Cancer Res 2008;68:3458-66.

20. Chen L, Lu D, Sun K, et al. Identification of biomarkers associated with diagnosis and prognosis of colorectal cancer patients based on integrated bioinformatics analysis. Gene 
2019;692:119-25.

21. Chen H, Liu Y, Jiang CJ, et al. Calcium-Activated Chloride Channel A4 (CLCA4) Plays Inhibitory Roles in Invasion and Migration Through Suppressing Epithelial-Mesenchymal Transition via PI3K/AKT Signaling in Colorectal Cancer. Med Sci Monit 2019;25:4176-85.

22. Kim SB, Calmet FH, Garrido J, et al. Sucrase-Isomaltase Deficiency as a Potential Masquerader in Irritable Bowel Syndrome. Dig Dis Sci 2020;65:534-40.

23. Wei FZ, Mei SW, Wang ZJ, et al. Differential Expression Analysis Revealing CLCA1 to Be a Prognostic and Diagnostic Biomarker for Colorectal Cancer. Front Oncol 2020;10:573295.

24. Chow PH, Bowen J, Yool AJ. Combined Systematic Review and Transcriptomic Analyses of Mammalian Aquaporin Classes 1 to 10 as Biomarkers and Prognostic Indicators in Diverse Cancers. Cancers (Basel) 2020;12:1911.

25. Zhang X, Zhang H, Shen B, et al. Chromogranin-A Expression as a Novel Biomarker for Early Diagnosis of Colon Cancer Patients. Int J Mol Sci 2019;20:2919.

26. Yang H, Lu Y, Lan W, et al. Down-regulated Solute Carrier Family 4 Member 4 Predicts Poor Progression in Colorectal Cancer. J Cancer 2020;11:3675-84.

27. Liu BX, Huang GJ, Cheng HB. Comprehensive Analysis of Core Genes and Potential Mechanisms in Rectal Cancer. J Comput Biol 2019;26:1262-77.

28. Zhuo C, Wu X, Li J, et al. Chemokine (C-X-C motif) ligand 1 is associated with tumor progression and poor prognosis in patients with colorectal cancer. Biosci Rep 2018;38:BSR20180580.

29. Choe EK, Yi JW, Chai YJ, et al. Upregulation of the adipokine genes ADIPOR1 and SPP1 is related to poor survival outcomes in colorectal cancer. J Surg Oncol 2018;117:1833-40.

30. Gutfeld O, Prus D, Ackerman Z, et al. Expression of serum

Cite this article as: Wen L, Han Z, Du Y. Identification of gene biomarkers and immune cell infiltration characteristics in rectal cancer. J Gastrointest Oncol 2021;12(3):964-980. doi: 10.21037/jgo-21-255 amyloid A, in normal, dysplastic, and neoplastic human colonic mucosa: implication for a role in colonic tumorigenesis. J Histochem Cytochem 2006;54:63-73.

31. Hansen MT, Forst B, Cremers N, et al. A link between inflammation and metastasis: serum amyloid A1 and A3 induce metastasis, and are targets of metastasis-inducing S100A4. Oncogene 2015;34:424-35.

32. Zhu J, Chen X, Liao Z, et al. TGFBI protein high expression predicts poor prognosis in colorectal cancer patients. Int $\mathrm{J}$ Clin Exp Pathol 2015;8:702-10.

33. Zhang Z, Wang Y, Zhang J, et al. COL1A1 promotes metastasis in colorectal cancer by regulating the WNT/PCP pathway. Mol Med Rep 2018;17:5037-42.

34. Hou L, Liu P, Zhu T. Long noncoding RNA SLC30A10 promotes colorectal tumor proliferation and migration via miR-21c/APC axis. Eur Rev Med Pharmacol Sci 2020;24:6682-91.

35. Yamaguchi N, Weinberg EM, Nguyen A, et al. PCK1 and DHODH drive colorectal cancer liver metastatic colonization and hypoxic growth by promoting nucleotide synthesis. Elife 2019;8:52135.

36. Li W, Jin X, Guo S, et al. Comprehensive analysis of prognostic immune-related genes in the tumor microenvironment of colorectal cancer. Aging (Albany NY) 2021;13:5506-24.

37. Jochems C, Schlom J. Tumor-infiltrating immune cells and prognosis: the potential link between conventional cancer therapy and immunity. Exp Biol Med (Maywood) 2011;236:567-79.

38. Roelands J, Kuppen PJK, Vermeulen L, et al. Immunogenomic Classification of Colorectal Cancer and Therapeutic Implications. Int J Mol Sci 2017;18:2229.

(English Language Editor: J. Reynolds) 


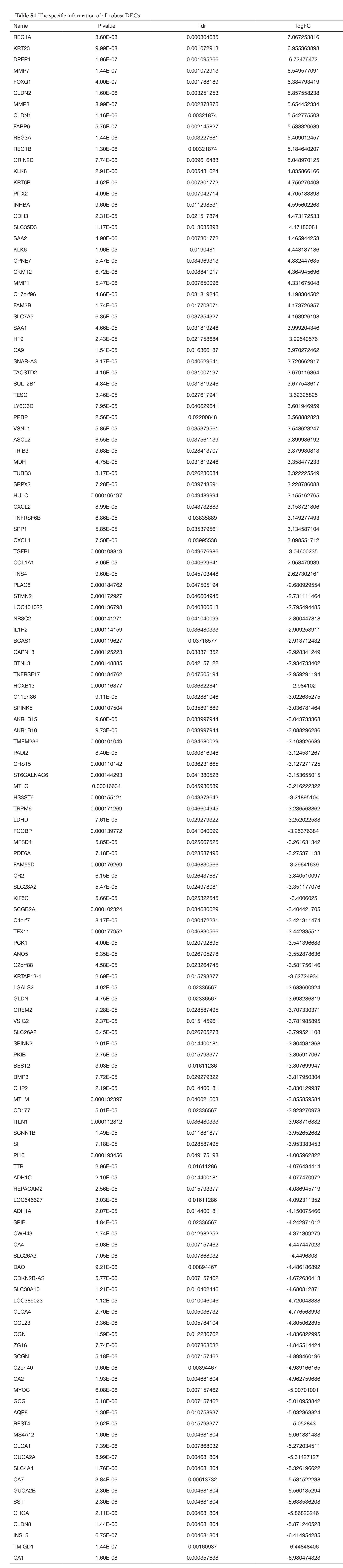


G0:0043588 skin development

G0:0016338 calcium-independent cell-cell achesion via
plasma membrane cell-lachesion molocules

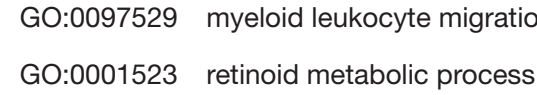

60:0001523 retinoid metabolic process
G0:0030593 neurtophic chemotaxis

G0:009656 anion transmembrane transport

G0:0003595 leukocyte chemotarys

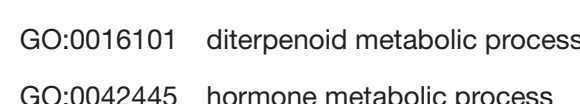

G0:0000326 cell chemotaxis

G0:004545 response to steroich hormone

60.0032963 collagen metabolic procoss

60:0045177 apical part of coll

60:001 6324 apical plasma memberso

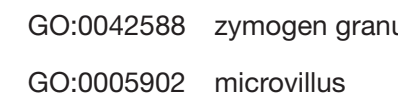

G0:00031253 cell projection membrane

60:0031526 brush border membrane
G0:0098858 actin-ased cell projection

G0.0031528 microvilus membran

G0:0005903 brush border

60:001 0323 basolatera plasma membrane

60.0098862 cluster of actin-based cell rojedections

G0.0031225 anchorored componenent of ment

Go:0031983 vesicile lumen

G0:00048018 receppor igand activity

60.0030546 signaling receptor activator activity

60:00040899 carbonate dehydratasse activity

G0:0070092 oligosaccharide binding

G0:001500 - horded transmembrane transooter activity

60:0015103 inoragnic anion transmembrane trasspoter

60:005125 cytokine active

G0:0016836 hydro-yase activity

60.00005254 chloridd channe activity

60:0005229 intracellulur calcium activiated chlor

G0.0061778 intracelluar cholidide chamel activity

60:0006 7788 intracelluar chloride
G0:0005179
cocrmone activity

60:0042834 peptidogylycan binding

60:0008009 chemokine activity

60.0005253 anion channel activi

60:0005509 anion transmembrane transporter actu

60.0001664 G protetin-coupled receptor binding

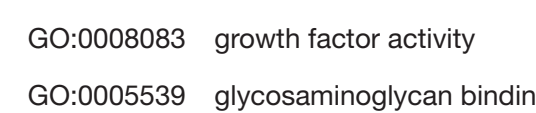

G0.0042379 chemokkne recepporob binding

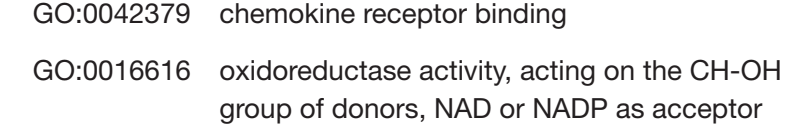

60.0000237 metallopesitidase activin

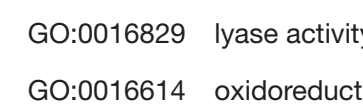

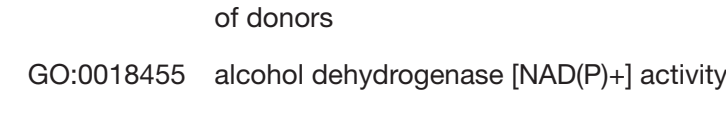

60:00195311 oxalate transmembraa

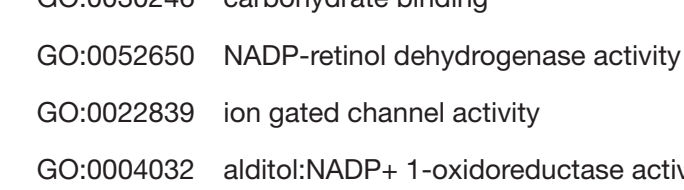

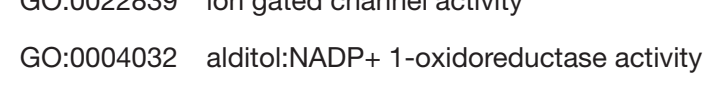

60.0008271 secondany active su

GQ:0004252 serine-type endo
G0:0015267 channel activity

60:0022803 passive transmembrane transooter activy

G0:0015116 sulfatet transmembrane transpotere activity

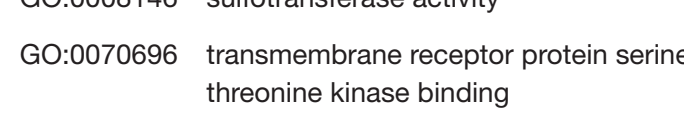

60.0000236 serine-type peptidiase activity

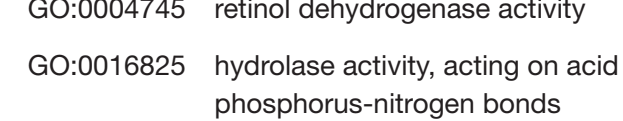

G0:0017171 seine hydrolase accily

60:0005216 ion channel activity

60:0008106 alcohol dehydrogenase (NADPF) activity

60:0004860 protetin kinase inibitior active

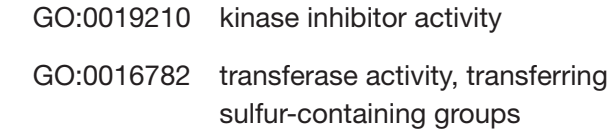

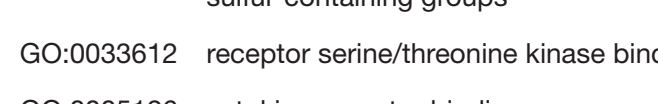

60:0005126 cyrtokine recester binding

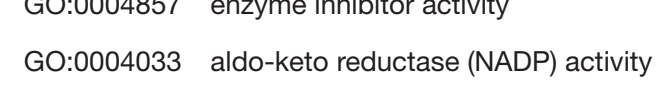

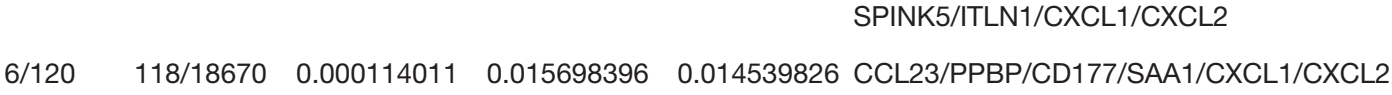

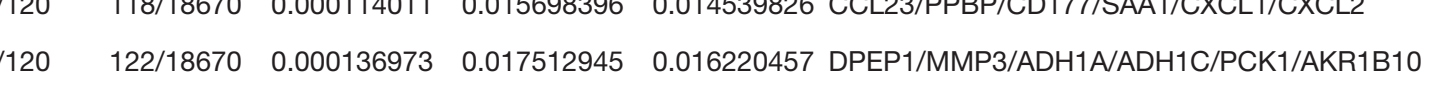

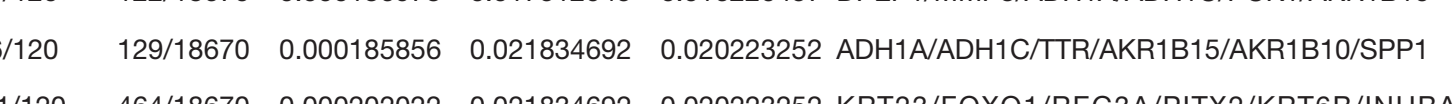

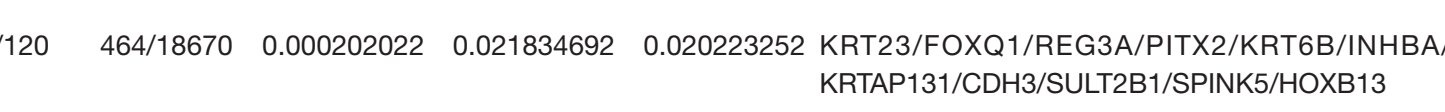

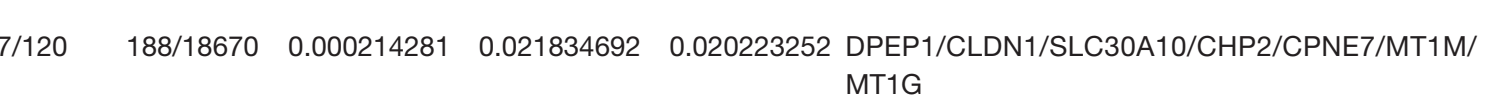

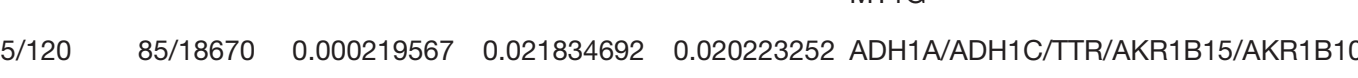

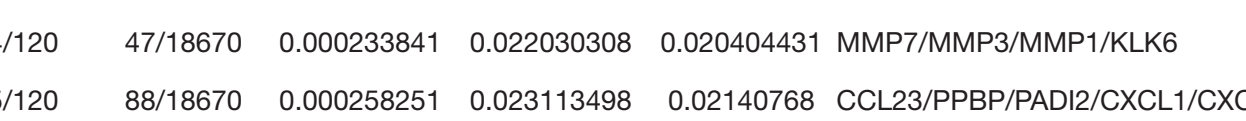

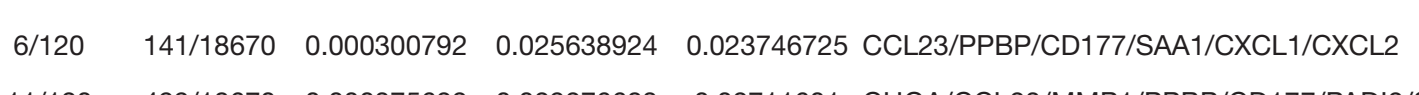

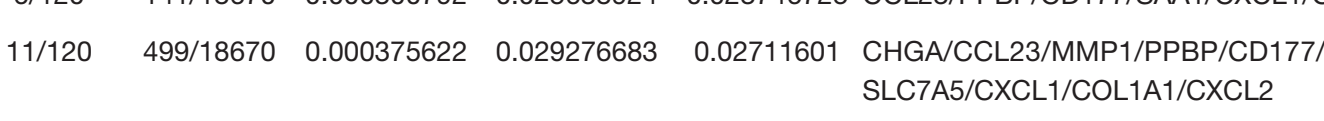

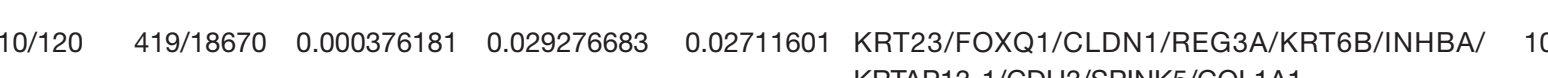

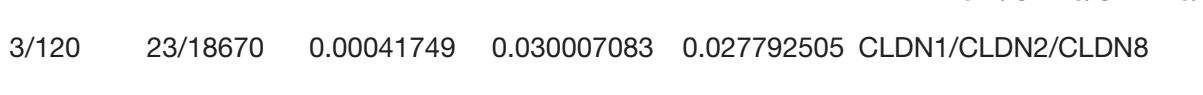

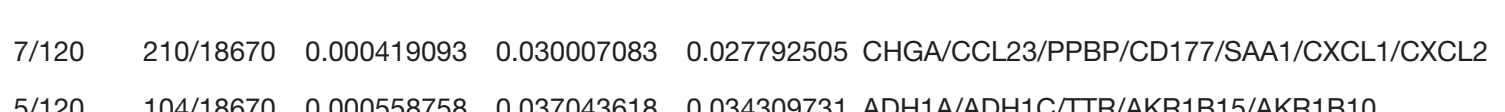

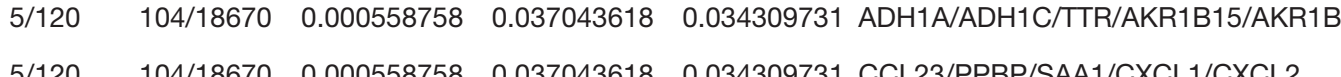

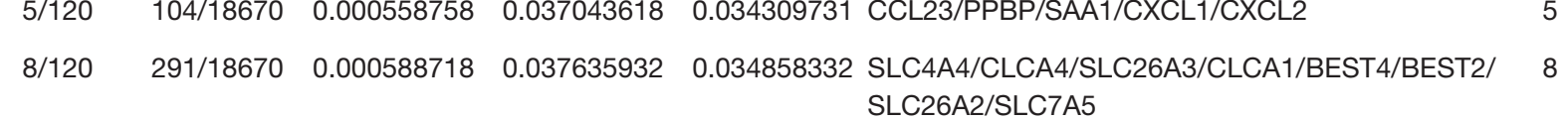

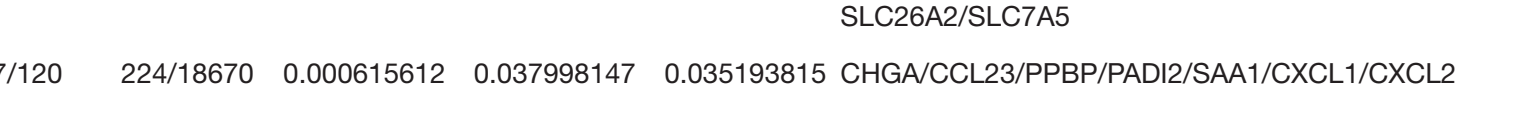

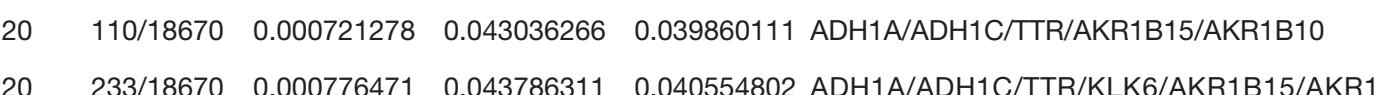

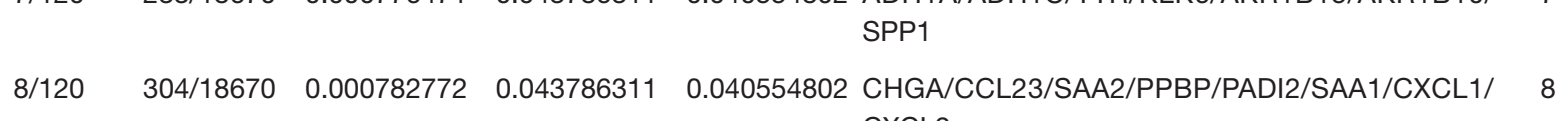

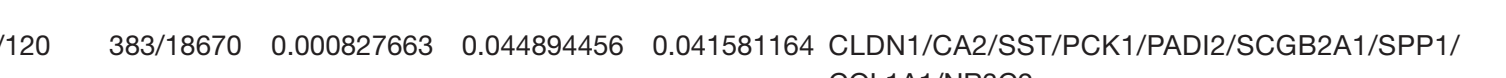

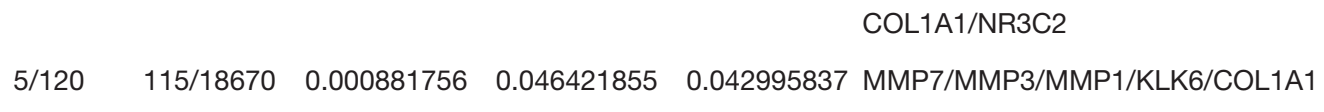

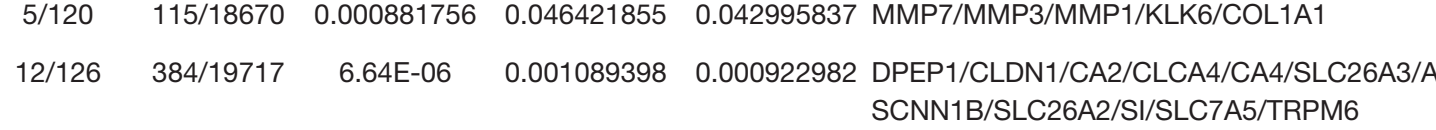

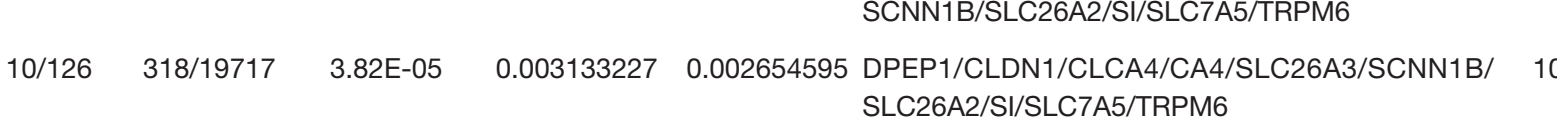

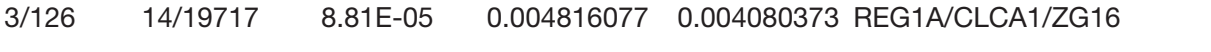

\begin{tabular}{lllll}
$5 / 126$ & $83 / 9717$ & 0.00019182 & 0.007864638 & 0.006663237 \\
\hline
\end{tabular}

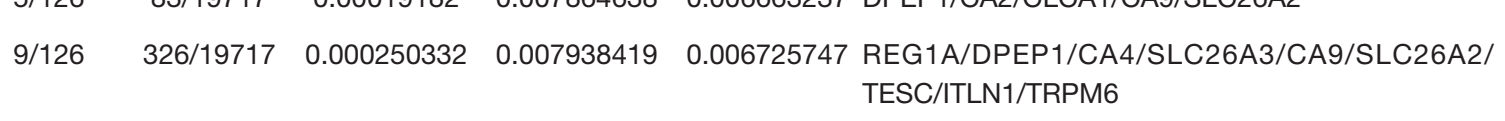

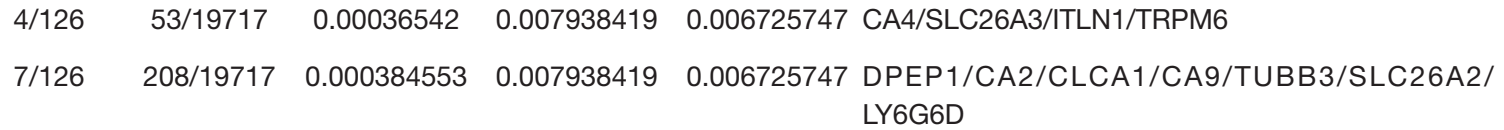

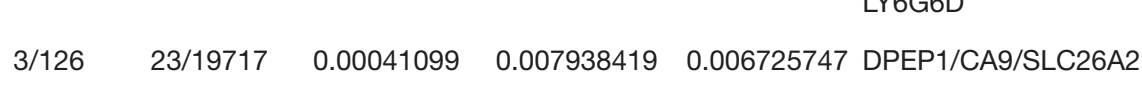

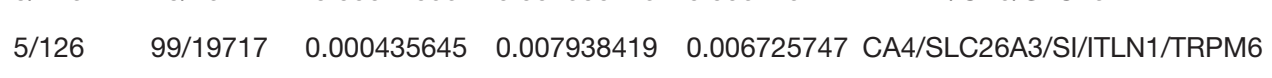

$2 / 126 \quad 11 / 19717 \quad 0.002145814 \quad 0.03519135 \quad 0.029815521$ CLCA1/ZG16

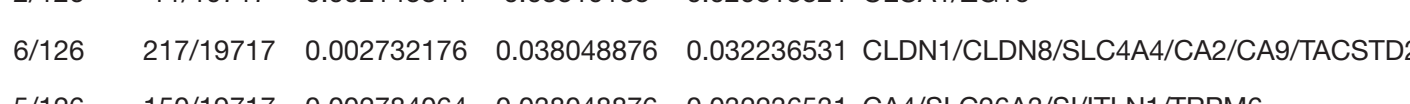

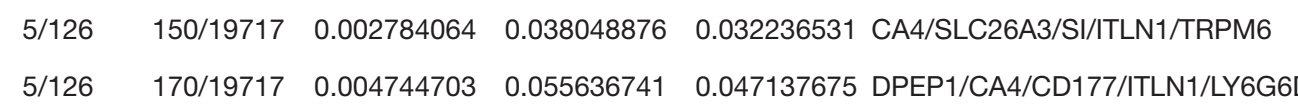

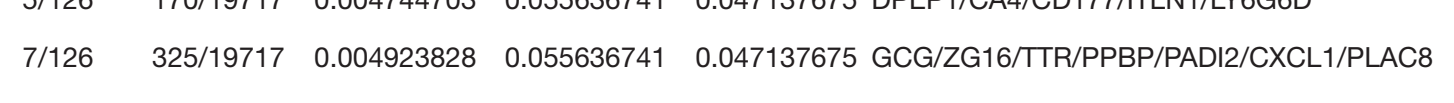

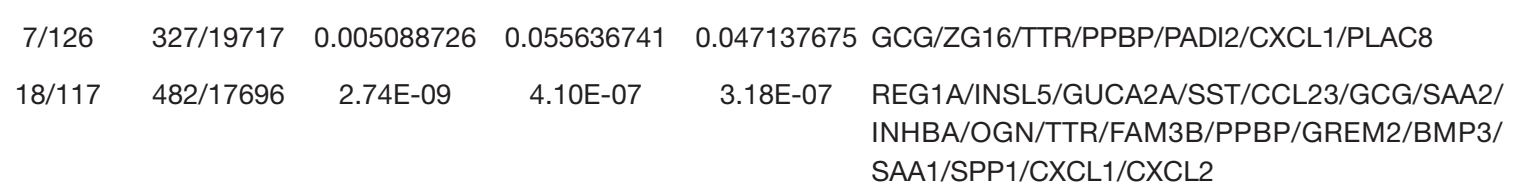

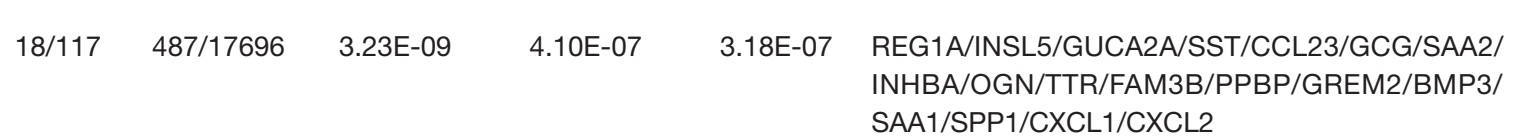

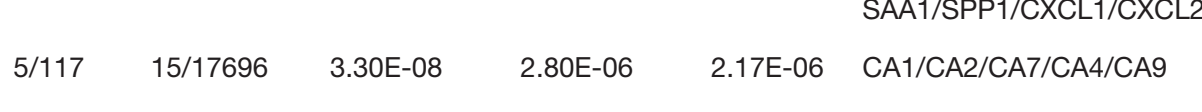

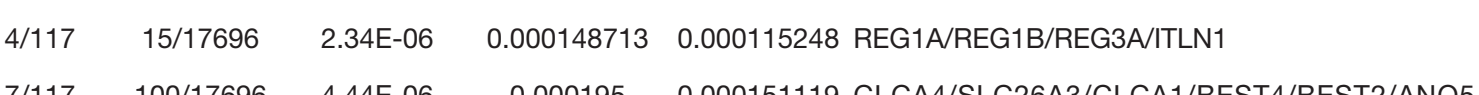

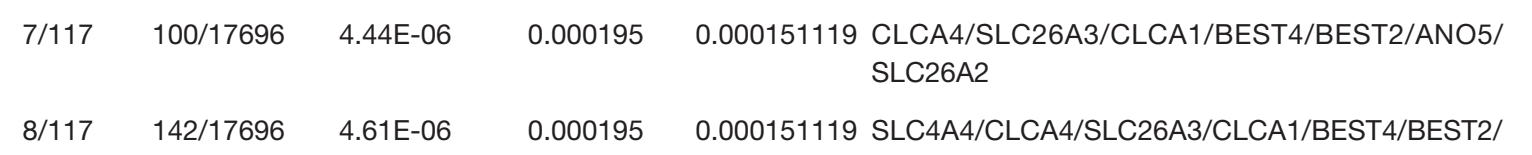

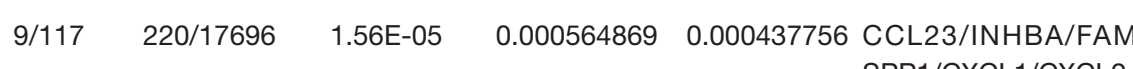

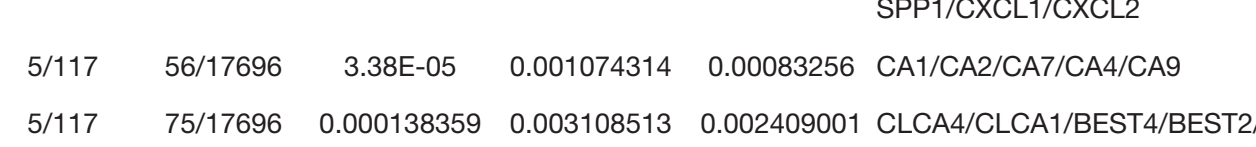

5117 7517009

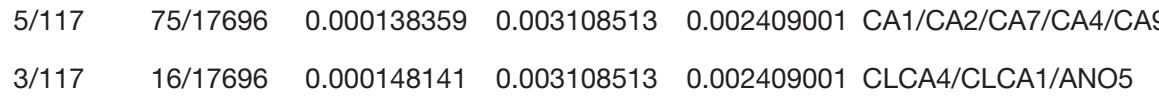

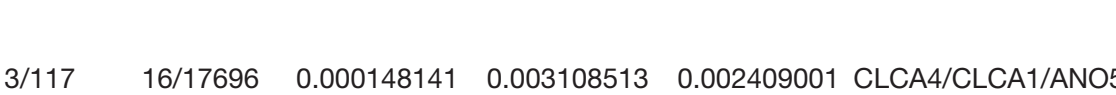

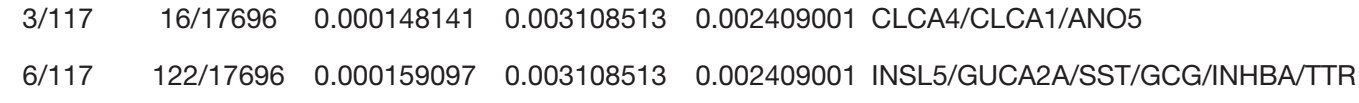

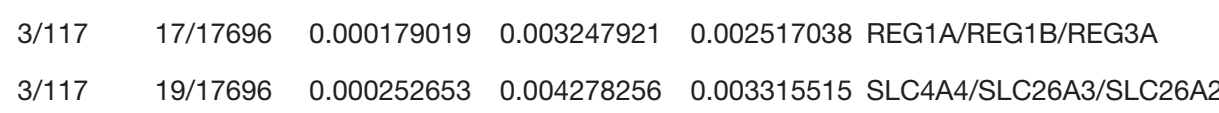

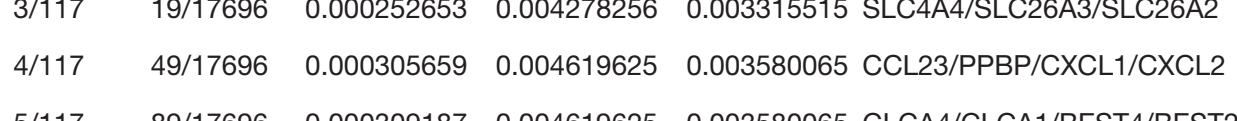

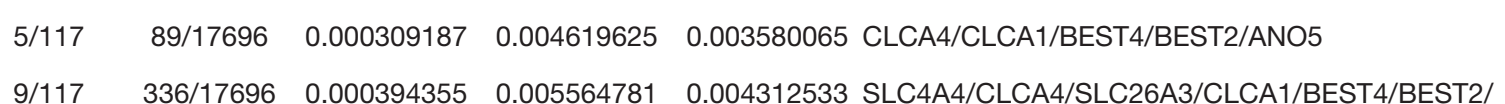

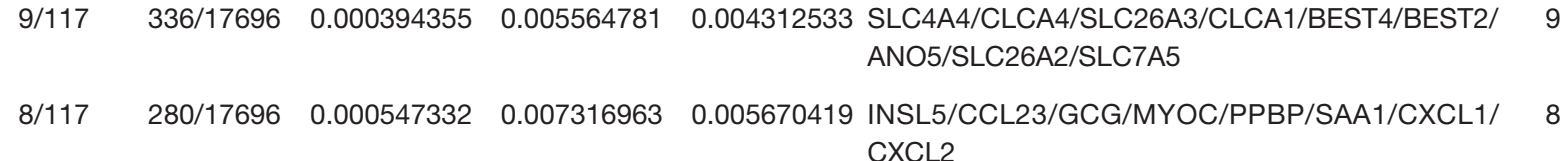

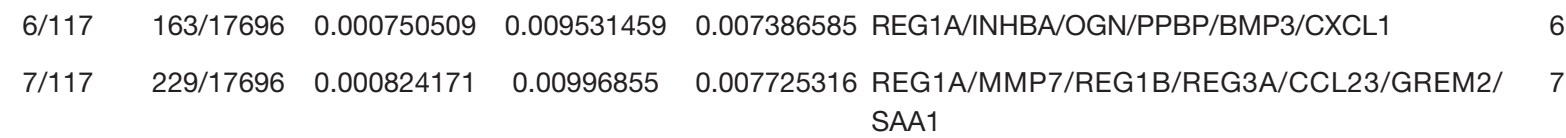

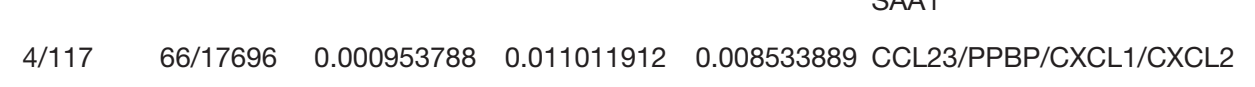

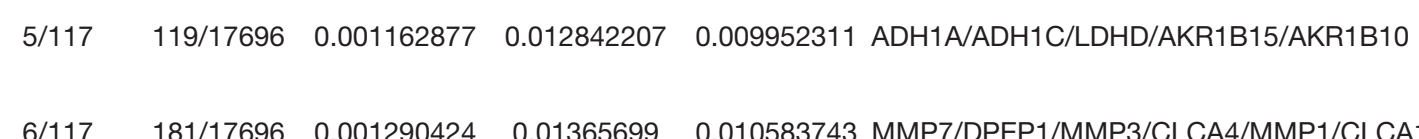

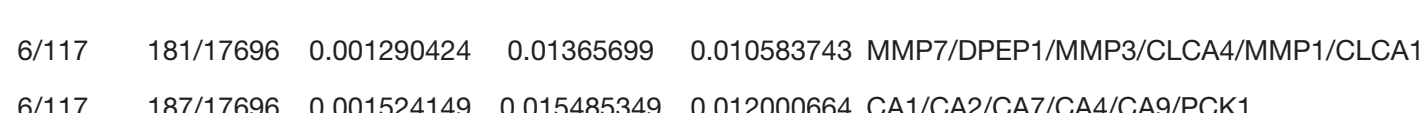

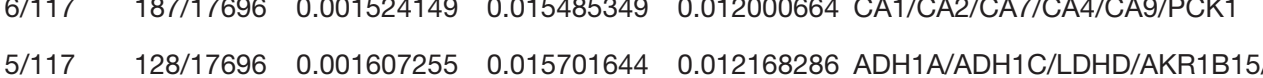

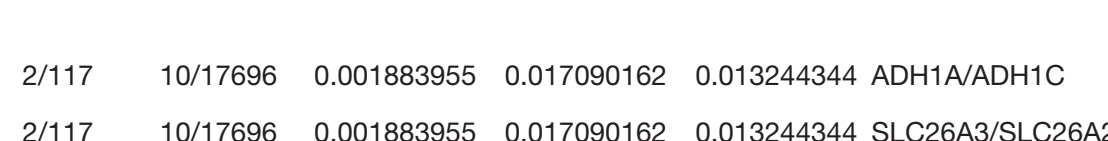

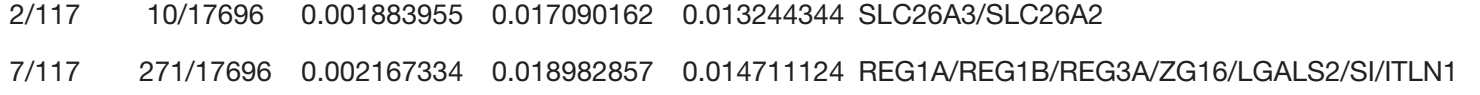

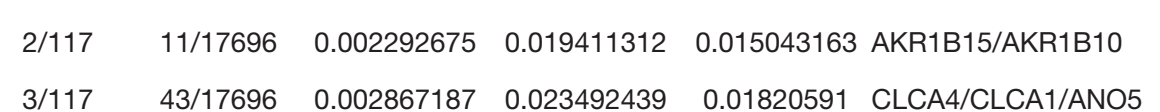

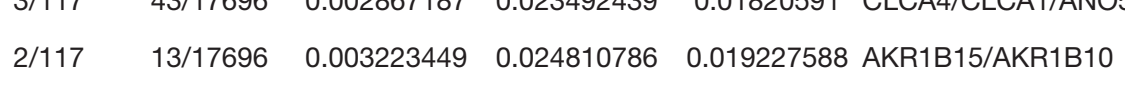

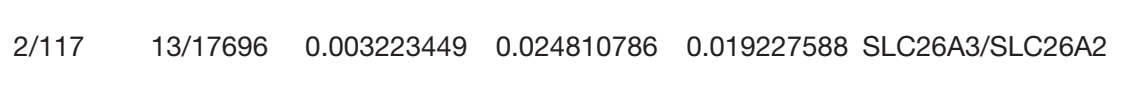

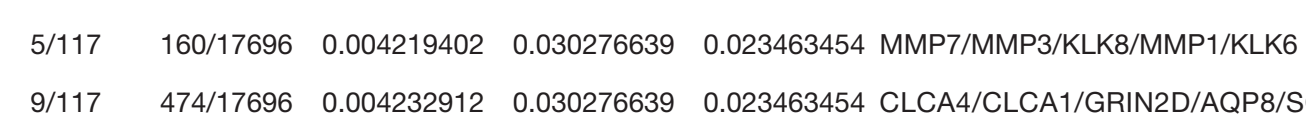

BEST/ANOSTRPME

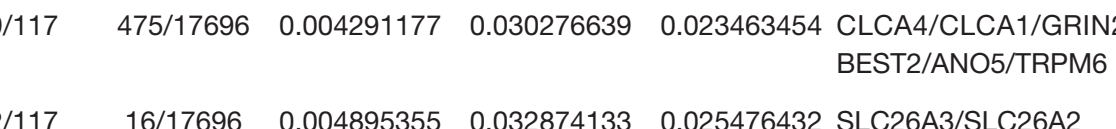

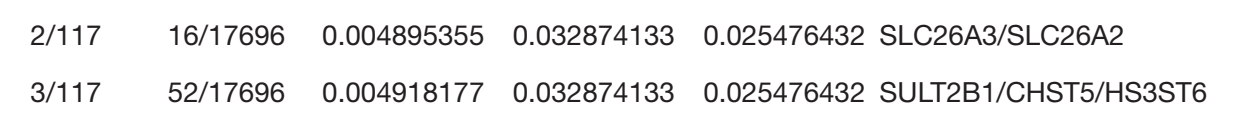

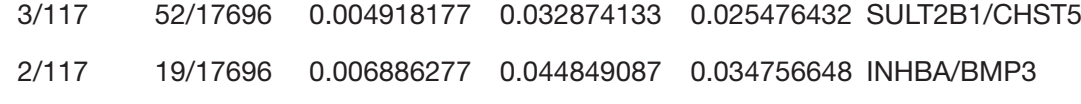

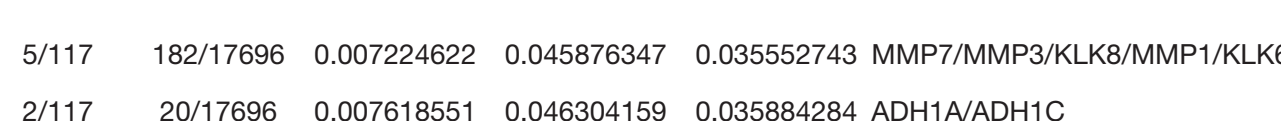

.

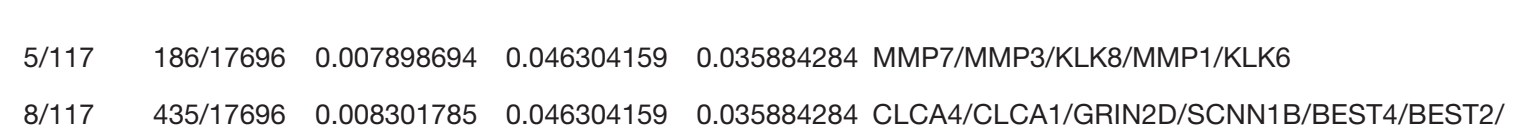

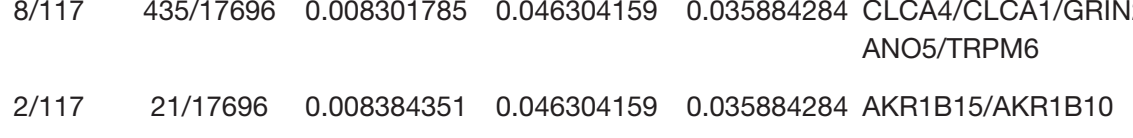

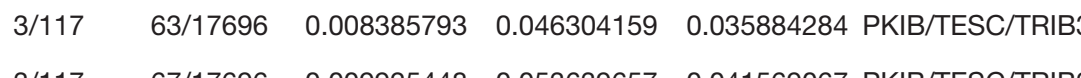

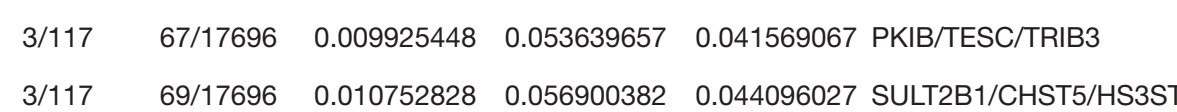

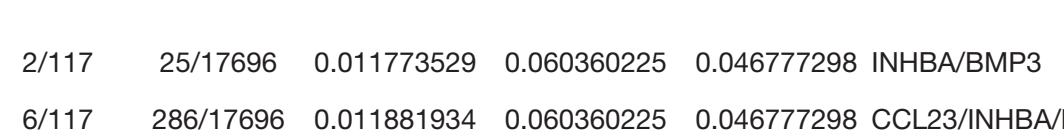

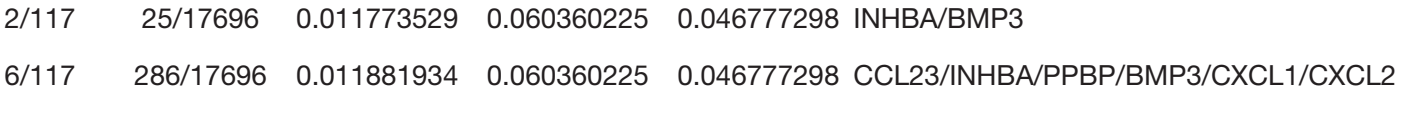

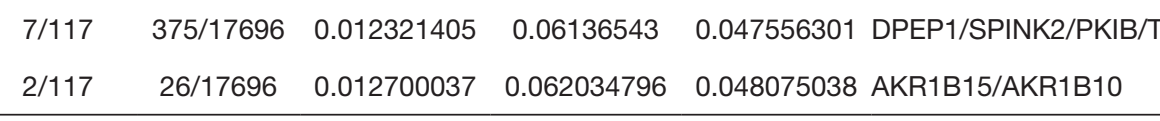




\begin{tabular}{|c|c|c|c|c|c|c|c|c|}
\hline ID & Description & Gene ratio & Bg ratio & P value & p.adjust & q value & Gene ID & Count \\
\hline hsa00910 & Nitrogen metabolism & 5/59 & $17 / 8102$ & $9.97 \mathrm{E}-08$ & $1.16 \mathrm{E}-05$ & $9.97 \mathrm{E}-06$ & CA1/CA2/CA $7 / C A 4 / C A 9$ & 5 \\
\hline hsa04964 & Proximal tubule bicarbonate reclamation & 4/59 & 23/8102 & $2.03 \mathrm{E}-05$ & 0.001174916 & 0.001012859 & SLC4A4/CA2/CA4/PCK1 & 4 \\
\hline hsa04060 & Cytokine-cytokine receptor interaction & 9/59 & $295 / 8102$ & 0.000251876 & 0.00973919 & 0.008395854 & CCL23/NHBA/PPBP/BMP3/LIR2/TNFRSF6B/CXCL/CXCL2/NFRSF17 & 9 \\
\hline hsa00620 & Pyruvate metabolism & $4 / 59$ & 47/8102 & 0.000358211 & 0.010388126 & 0.008955281 & ADH1A/ADH1C/PCK1/LDHD & 4 \\
\hline hsa04972 & Pancreatic secretion & $5 / 59$ & 102/8102 & 0.000837155 & 0.016559945 & 0.014275815 & SLC4A4/CA2/CLCA4/SLC26A3/CLCA1 & 5 \\
\hline hsa04978 & Mineral absorption & 4/59 & 59/8102 & 0.000856549 & 0.016559945 & 0.014275815 & SLC26A3/MT1MMT11G/RPM6 & 4 \\
\hline
\end{tabular}

GO:0031284 positive regulation of guanylate cyclase activity

10/18670 $\quad 6.49 E-05 \quad 0.002374256 \quad 0.001512346 \quad$ GUCA2AGGUCA2B

$\begin{array}{lllll}368 / 18670 & 7.27 E-05 & 0.002393714 & 0.001524741 & \text { MMP1/TR/SPP1/TGFB//COL1A1 }\end{array}$

GQ:0030198 extracellular matrix organization

GO:0043062 extracellular structure organization

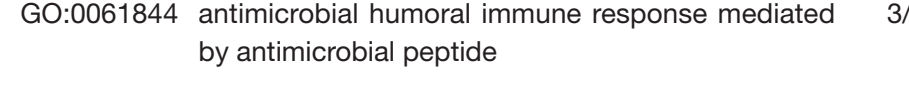

\section{GO:0070098 chemokine-mediated signaling pathw}

GO:1902476 chloride transmembrane

GO:1990869 cellular response to chemokine

GO:0006821 chloride transport

GO:0031281 positive regulation of cyclase activity

GQ:0098661 inorganic anion transmembrane transport

GO:0043200 response to amino acid

GO:0010447 response to acidic $p$ H

GO.0030810 positive regulation of nuc

GO:0051349 positive regulation of lyase activity

GO:1900373 positive regulation of purine nucleotide biosynthetc

$\begin{array}{lll}12 / 118670 & 9.51 E-05 & 0.002000\end{array}$

$\begin{array}{llllll}88 / 18670 & 0.000167377 & 0.004450694 & 0.00283499 & \text { PPBP/CXCL1/CXCL2 }\end{array}$

$\begin{array}{llllll}88 / 18670 & 0.000167377 & 0.004450694 & 0.00283499 & \text { CLCA4/SLC26A3/CLCA1 }\end{array}$

$\begin{array}{lllll}97 / 18670 & 0.000223266 & 0.0054421 & 0.003466493 & \text { PPBP/CXCL1/CXCL2 }\end{array}$

$\begin{array}{lllll}97 / 18670 & 0.000223266 & 0.0054421 & 0.003466493 & \text { PPBP/CXCL1/CXCL2 }\end{array}$

$\begin{array}{lllll}108 / 18670 & 0.000306431 & 0.006609567 & 0.004210143 & \text { CLCA4/SLC26A3/CLCA }\end{array}$

$\begin{array}{llllll}22 / 18670 & 0.000330357 & 0.006609567 & 0.004210143 & \text { GUCA2AGGCA2B }\end{array}$

$\begin{array}{lllll}111 / 118670 & 0.000332136 & 0.006609567 & 0.004210143 & \text { CLCA4/SLC26A3/CLCA1 }\end{array}$

$\begin{array}{lllll}113 / 18670 & 0.000350022 & 0.006609567 & 0.004210143 & \text { SST/PCK1/COLA1 }\end{array}$

$\begin{array}{llllll}23 / 18670 & 0.000361549 & 0.006609567 & 0.004210143 & \text { SST/PCK1 }\end{array}$

$\begin{array}{llll}23 / 18670 & 0.000361549 & 0.006600567 & 0.004210143\end{array} \quad$ GUCA2AGGUCA2B

$\begin{array}{lllllll}2 / 23 & 23 / 18670 & 0.000361549 & 0.006600567 & 0.004210143 & \text { GUCA2AGGUCA2B }\end{array}$

\section{GO:0098656 anion}

GO:0071377 cellular response to glucagon stimulus

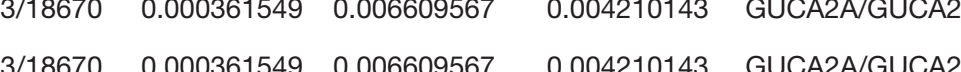

G0:0009914 hormone transport

G0:0032496 response to lipopolysaccharide

GO:0002237 response to molecule of bacterial origin

G0:0006959 humoral immune response

GO:0033762 response to glucagon

G0:0009268 response to pH

GO:1900371 regulation of purine nucleotide biosynthetic pro-

G0:0048545 response to steroid hormone

GQ:0030808 regulation of nucleotide biosynthetic process

GO:0015701 bicarbonate transport

GO:0031279 regulation of cyclase activity

G0:0045981 positive regulation of nucleotide metabolic process

GO:0051339 regulation of lyase activity

GO:1900544 positive regulation of purine nucleotide metabolic

$\begin{array}{lllll}291 / 18670 & 0.000405183 & 0.007182789 & 0.004575272 & \text { SLCAA4/CLCA4/SLC26A3/CLCA1 }\end{array}$

$\begin{array}{lllllll}26 / 18670 & 0.000463397 & 0.007973163 & 0.005078722 & \text { PCK1/GCG }\end{array}$

$\begin{array}{lllll}317 / 18670 & 0.000559542 & 0.009352338 & 0.005957225 & \text { CHGATTR/SPP1/GCG }\end{array}$

$\begin{array}{lllll}330 / 18670 & 0.000650676 & 0.01057348 & 0.006735064 & \text { PPBP/PCK } 1 / C X C L 1 / C X C L 2\end{array}$

$\begin{array}{lllll}3433 / 18670 & 0.000751923 & 0.011888518 & 0.007572713 & \text { PPBP/PCK1/CXCL1/CXCL2 }\end{array}$

$\begin{array}{lllll}356 / 18670 & 0.000863899 & 0.013299493 & 0.008471472 & \text { CHGA/PPBP/CXCL1/CXCL2 }\end{array}$

$\begin{array}{lllll}36 / 18670 & 0.000891575 & 0.013373619 & 0.008518688 & \text { PCK } 1 / G C G\end{array}$

$\begin{array}{lllll}40 / 18670 & 0.001100553 & 0.015703012 & 0.010002459 & \text { SST/PCK } 1\end{array}$

$\begin{array}{lllll}40 / 18670 & 0.001100553 & 0.015703012 & 0.010002459 & \text { GUCA2AGGUCA2B }\end{array}$

$\begin{array}{lllll}383 / 18670 & 0.001133428 & 0.015728687 & 0.010018813 & \text { SST/SPP1/PCK1/COL1A1 }\end{array}$

$\begin{array}{lllll}41 / 18670 & 0.001156126 & 0.015728687 & 0.010018813 & \text { GUCA2AGUCA2 }\end{array}$

$\begin{array}{llllll}42 / 18670 & 0.001213024 & 0.0161277 & 0.010272975 & \text { SLC4A4/SLC26A3 }\end{array}$

$\begin{array}{llllll}43 / 18670 & 0.001271243 & 0.016526165 & 0.010526788 & \text { GUCA2AGGUCA2B }\end{array}$

$\begin{array}{llllll}46 / 18670 & 0.001453805 & 0.017718246 & 0.011286116 & \text { GUCA2AGGUCA2B }\end{array}$

$\begin{array}{llllll}46 / 18670 & 0.001453805 & 0.017718246 & 0.011286116 & \text { GUCA2AGGUCA2B }\end{array}$

$\begin{array}{lllll}46 / 18670 & 0.001453805 & 0.017718246 & 0.011286116 & \text { GUCA2A/GUCA2B }\end{array}$

GO:0043434 response to peptide hormone

GO:0071222 cellular response to lipopolysaccharide

GO:0019935 cyclic-nucleotide-mediated signaling

GQ:0071219 cellular response to molecule of bacterial origi

GO:0007584 response to nutrient

GO:0007588 excretion

GO:0071216 cellular response to biotic stimulus

GO:0031667 response to nutrient levels

GO:0071300 cellular response to retinoic acid

GQ:0046883 regulation of hormone secretion

GQ:0051453 regulation of intracelluar

GO:00060205 cytooplasmic vesicle lum

GO:0031983 vesicle umen

GO:0031983 vesicle lumen

GO:1904724 tertiary granule lumen

GO:0005788 endoplasmic reticulum lumen

GO:0005903 brush border

G0:0016324 apical plasma membran

GO:0048018 receptor ligand activity

\section{GO:0030546 signaling receptor activator activity}

GO:0005179 hormone activity

GO:0001664 G protein-coupled receptor binding

GO:0015103 inorganic anion transmembrane transporter activity

G0:0008009 chemokine activity

GO:0042379 chemokine receptor binding

GO:0005125 cytokine activity

GO:0005229 intracellular calcium activated chloride channel ac-

tivity
GO:0061778 intracellular chloride channel activity

GO:0015106 bicarbonate transmembrane transporter activity

GO:0015108 chloride transmembrane transporter activity

GO-0008509 anion transmembrane transporter activity

G0:0022839 ion gated channel activity

G0:0008237 metallopeptidase activity

GO:0050840 extracellular matrix binding

GO:0005254 chloride channel activity

GO:0005126 cytokine receptor binding
GO:005253 anion channel activity

$\begin{array}{lllll}436 / 18670 & 0.001826249 & 0.021803172 & 0.01388812 & \text { SLC30A10/PCK1/COL1A1/GCG }\end{array}$

$\begin{array}{lllll}205 / 18670 & 0.001964707 & 0.022987067 & 0.014642234 & \text { PPBP/CXCL1/CXCL2 }\end{array}$

$\begin{array}{lllll}212 / 18670 & 0.002161811 & 0.024320372 & 0.015491519 & \text { CHGAGGUCA2B/GCG }\end{array}$

$\begin{array}{lllll}212 / 18670 & 0.002161811 & 0.024320372 & 0.015491519 & \text { PPBP/CXCL1/CXCL2 }\end{array}$

$\begin{array}{lllll}219 / 18670 & 0.002370845 & 0.026168759 & 0.016668899 & \text { SST/SPP1/COL1A1 }\end{array}$

$\begin{array}{lllll}63 / 18670 & 0.002708599 & 0.029343156 & 0.018690917 & \text { GUCA2B/SLC26A3 }\end{array}$

$\begin{array}{lllll}236 / 18670 & 0.002929681 & 0.031143503 & 0.019837697 & \text { PPBP/CXCL1/CXCL2 }\end{array}$

$\begin{array}{lllll}499 / 18670 & 0.002981258 & 0.031143503 & 0.019837697 & \text { SST/SPP } 1 / \text { PCK1/COLAA } 1\end{array}$

$\begin{array}{llllll}69 / 18670 & 0.003239085 & 0.03324324 & 0.021175181 & \text { PCK1/COL1A1 }\end{array}$

$\begin{array}{llllll}262 / 18670 & 0.003930896 & 0.039647826 & 0.025254756 & \text { CHGASPP } 1 / G C G\end{array}$

$\begin{array}{llllll}84 / 18670 & 0.004759422 & 0.047190879 & 0.030059507 & \text { SLC4A4/SLC26A3 }\end{array}$

$\begin{array}{lllll}321 / 19717 & 0.000566363 & 0.011535838 & 0.00745622 & \text { TR/PPBP/CXCL//GCG }\end{array}$

$\begin{array}{lllll}325 / 19717 & 0.000593329 & 0.011535838 & 0.00745622 & \text { TRR/PPBP/CXCL//GCG }\end{array}$

$\begin{array}{llllll}327 / 19717 & 0.000607149 & 0.011535838 & 0.00745622 & \text { TRR/PPBP/CXCL//GCG }\end{array}$

$\begin{array}{lllll}384 / 19717 & 0.001105281 & 0.01575026 & 0.010180223 & \text { CLCA4/SLC26A3/AQP8/SI }\end{array}$

$\begin{array}{lllll}55 / 19717 & 0.002027219 & 0.023110296 & 0.014937403 & \text { PPBP/CXCL1 }\end{array}$

$\begin{array}{llllll}309 / 19717 & 0.00604535 & 0.046625468 & 0.030136498 & \text { SPP1/COL1A1/GCG }\end{array}$

$\begin{array}{lllll}99 / 19717 & 0.00640979 & 0.046625468 & 0.030136498 & \text { SLC26A3/SI } \\ 318 / 19717 & 0.006543925 & 0.046625468 & 0.030136498 & \text { CLCA4/SLC26A3/SI }\end{array}$

$\begin{array}{llllll}482 / 17696 & 2.78 E-09 & 1.38 E-07 & 6.89 E-08 & \text { GUCA2ASST/TR/PPBP/SAA1/SPP1/ } \\ \text { CXCL1/GCG/CXCL2 }\end{array}$

$\begin{array}{ccccc}487 / 17696 & 3.04 E-09 & 1.38 E-07 & 6.89 E-08 & \begin{array}{l}\text { GUCA2ASST/RR/PPBP/SAA1/SPP1/ } \\ \text { CXCL1//GCG/CXC12 }\end{array}\end{array}$

$\begin{array}{lllll}122 / 17696 & 1.43 E-05 & 0.000433406 & 0.000215575 & \text { GUCA2A/SST/TR/GCG }\end{array}$

$\begin{array}{lllll}280 / 17696 & 2.02 E-05 & 0.000449057 & 0.00022336 & \text { PPBP/SAA } 1 / C X C L 1 / G C G / C X C L 2\end{array}$

$\begin{array}{lllll}142 / 17696 & 2.60 E-05 & 0.000449057 & 0.00022336 & \text { SLCAA4/CLCA4/SLC26A3/CLCA1 }\end{array}$

$\begin{array}{lllll}49 / 17696 & 2.96 E-05 & 0.000449057 & 0.00022336 & \text { PPBP/CXCL1/CXCL2 }\end{array}$

$\begin{array}{llllll}66 / 17696 & 7.25 E-05 & 0.000942998 & 0.000469044 & \text { PPBP/CXCL1/CXCL2 }\end{array}$

$\begin{array}{llllll}220 / 17696 & 0.000142613 & 0.001594252 & 0.000792977 & \text { PPBP/SPP1/CXCL1/CXCL2 }\end{array}$

$\begin{array}{llllll}16 / 17696 & 0.000175193 & 0.001594252 & 0.000792977 & \text { CLCA4/CLCA1 }\end{array}$

$\begin{array}{llllll}16 / 17696 & 0.000175193 & 0.001594252 & 0.000792977 & \text { CLCA4/CLCA }\end{array}$

$\begin{array}{lllll}19 / 17696 & 0.000249086 & 0.00189131 & 0.000940733 & \text { SLC4A4/SLC26A3 }\end{array}$

$\begin{array}{lllll}100 / 17696 & 0.000249404 & 0.00189131 & 0.000940733 & \text { CLCA4/SLC26A3/CLCA1 }\end{array}$

$\begin{array}{lllll}336 / 17696 & 0.00071252 & 0.00498764 & 0.002480839 & \text { SLCAA4/CLCA4/SLC26A3/CLCA1 }\end{array}$

$\begin{array}{lllll}43 / 17696 & 0.0012918 & 0.008396699 & 0.004176496 & \text { CLCA4/CLCA1 }\end{array}$

$\begin{array}{lllll}43 / 17696 & 0.0012918 & 0.008396069 & 0.004776496 & \text { CLCAA//LCA1 } \\ 181 / 17696 & 0.001404558 & 0.008520984 & 0.004238315 & \text { CLCAA/MMP1/CLCA1 }\end{array}$

$\begin{array}{lllll}57 / 17696 & 0.002259271 & 0.012849607 & 0.00639136 & \text { SPP1/TGFBI }\end{array}$

$\begin{array}{lllll}75 / 17696 & 0.003875479 & 0.020745209 & 0.010318612 & \text { CLCA4/CLCA1 }\end{array}$

$\begin{array}{lllll}286 / 17696 & 0.005124041 & 0.025904876 & 0.012885016 & \text { PPBP/CXCL//CXC } \\ 89 / 17696 & 0.00541179 & 0.025919628 & 0.012892354 & \text { CLCA/CLCA1 }\end{array}$ 
Table S5 KEGG pathway enrichment analysis of hub genes

\begin{tabular}{llcccccc}
\hline ID & Description & Gene ratio & Bg ratio & P value & p.adjust & q value & Gene ID \\
\hline hsa04972 & Pancreatic secretion & $4 / 16$ & $102 / 8104$ & $3.83 E-05$ & 0.002031543 & 0.001291149 & SLC4A4/CLCA4/SLC26A3/CLCA1 \\
hsa05323 & Rheumatoid arthritis & $3 / 16$ & $93 / 8104$ & 0.000735285 & 0.008501102 & 0.005402885 & MMP1/CXCL1/CXCL2 \\
hsa04657 & IL-17 signaling pathway & $3 / 16$ & $94 / 8104$ & 0.000758609 & 0.008501102 & 0.005402885 & MMP1/CXCL1/CXCL2 \\
hsa04964 & Proximal tubule bicarbonate reclamation & $2 / 16$ & $23 / 8104$ & 0.000902567 & 0.008501102 & 0.005402885 & SLC4A4/PCK1 \\
hsa04061 & Viral protein interaction with cytokine and cytokine receptor & $3 / 16$ & $100 / 8104$ & 0.000908527 & 0.008501102 & 0.005402885 & PPBP/CXCL1/CXCL2 \\
hsa05146 & Amoebiasis & $3 / 16$ & $102 / 8104$ & 0.000962389 & 0.008501102 & 0.005402885 & CXCL1/COL1A1/CXCL2 \\
\hline
\end{tabular}

A

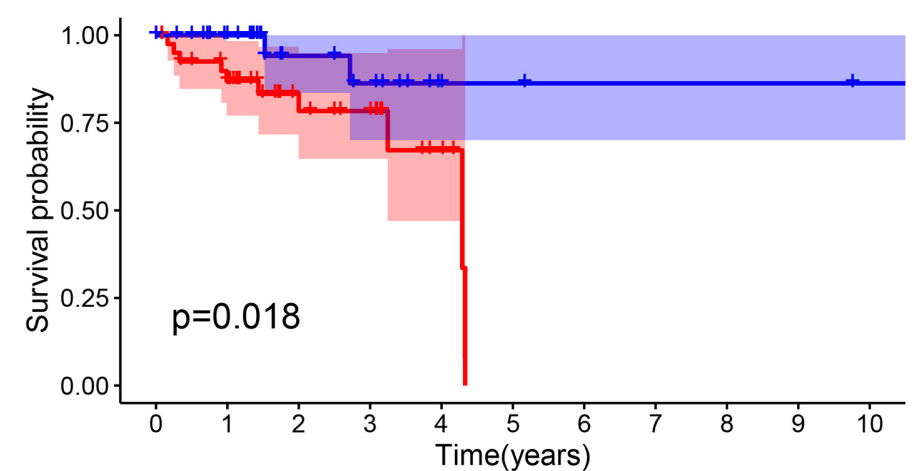

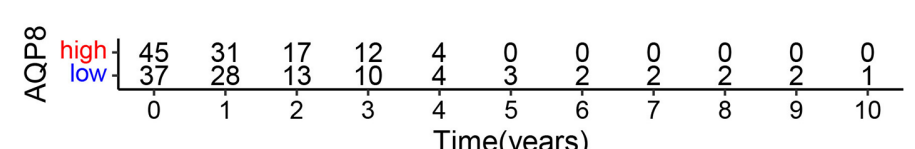

C

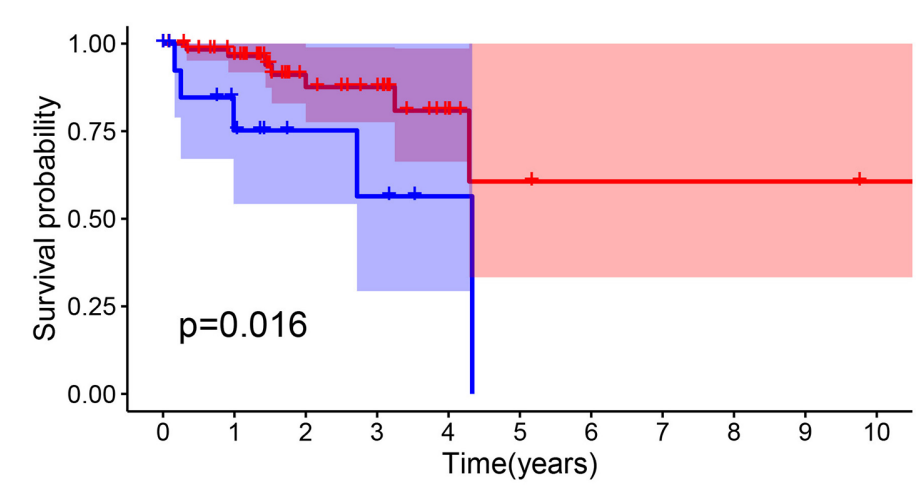

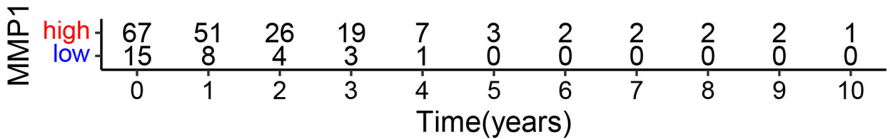

B

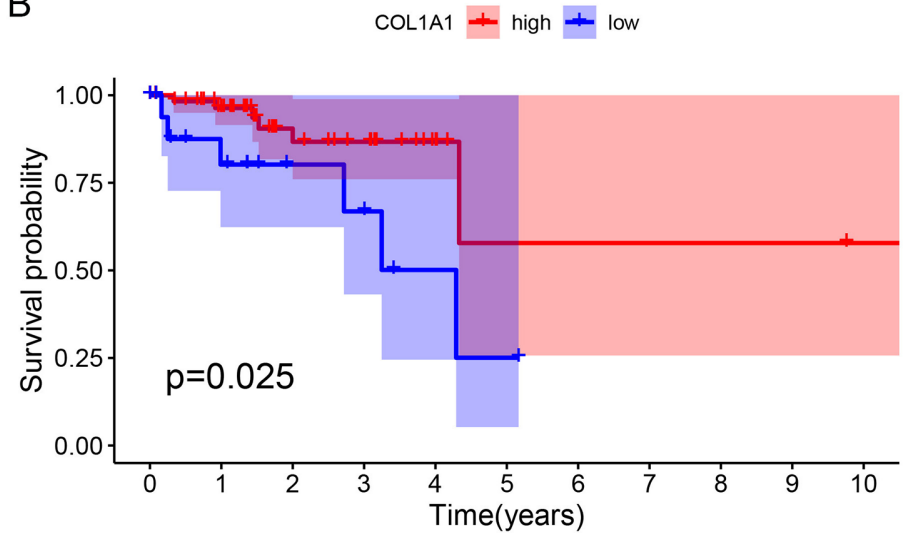

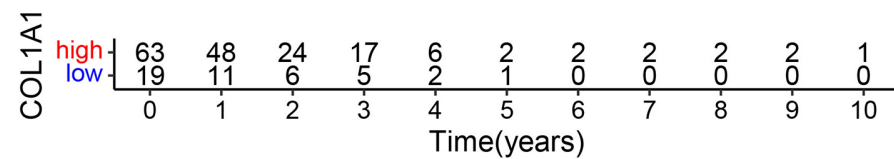

D

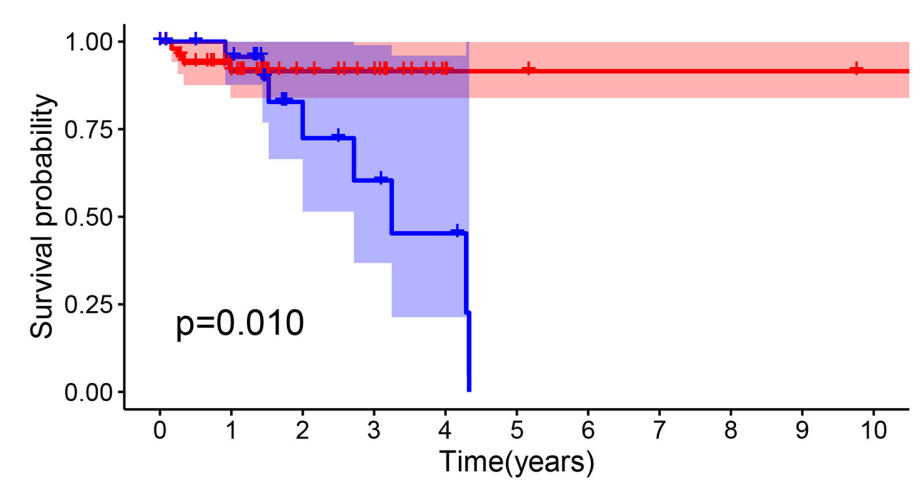

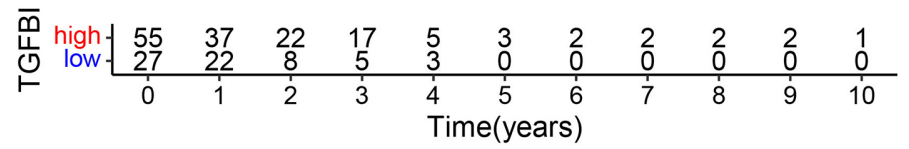

Figure S1 Survival analysis of the 24 hub genes. Gene changes of AOP8 (A), COLIA1 (B), MMP1 (C), and TGFBI (D) were significantly correlated with the overall survival ofpatients with rectal cancer (P<0.05).
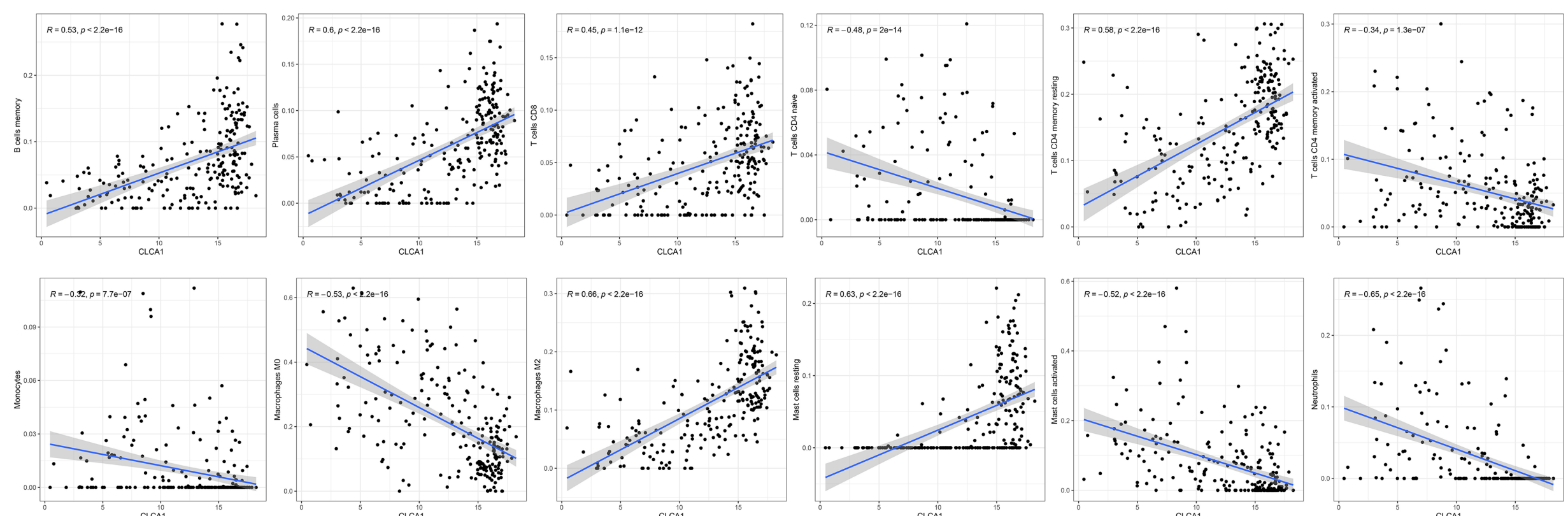

Figure S2 Relationship between the prognostic gene CLCA1 and immune cell infiltration. 